\title{
Vocal rhythms in nesting Lusitanian toadfish, Halobatrachus didactylus
}

\author{
Manuel Vieira $^{\text {a,b, },}$, M. Clara P. Amorim ${ }^{\mathrm{b}, 1}$, Paulo J. Fonseca ${ }^{\mathrm{a}}$ \\ ${ }^{a}$ Departamento de Biologia Animal and cE3c, Centre for Ecology, Evolution and Environmental Changes, Faculdade de Ciências, Universidade de Lisboa, Bloco C2. \\ Campo Grande, 1749-016 Lisboa, Portugal \\ ${ }^{\mathrm{b}}$ MARE - Marine and Environmental Sciences Centre, ISPA - Instituto Universitário, Rua Jardim do Tabaco 34, 1149-041 Lisboa, Portugal
}

\section{A R T I C L E I N F O}

\section{Keywords:}

Acoustic interactions

Fish acoustic communication

Passive acoustic monitoring

Effect of tide

Batrachoididae

Fish chorus

\begin{abstract}
A B S T R A C T
Males of several fish species aggregate and vocalize together, increasing the detection range of the sounds and their chances of mating. In the Lusitanian toadfish (Halobatrachus didactylus), breeding males build nests under rocks in close proximity and produce hundreds of boatwhistles (BW) an hour to attract females to lay their demersal eggs on their nests. Chorusing behaviour includes fine-scale interactions between individuals, a behavioural dynamic worth investigating in this highly vocal fish. Here we present a study to further investigate this species' vocal temporal patterns on a fine (individual rhythms and male-male interactions) and large (chorus daily patterns) scales. Several datasets recorded in the Tagus estuary were labelled with the support of an automatic recognition system based on hidden Markov models. Fine-scale vocal temporal patterns exhibit high variability between and within individuals, varying from an almost isochronous to an apparent aperiodic pattern. When in a chorus, males exhibited alternation or synchrony calling patterns, possibly depending on motivation and social context (mating or male-male competition). When engaged in sustained calling, males usually alternated vocalizations with their close neighbours thus avoiding superposition of calls. Synchrony was observed mostly in fish with lower mean calling rate. Interaction patterns were less obvious in more distanced males. Daily choruses showed periods with several active calling males and periods of low activity with no significant diel patterns in shallower intertidal waters. Here, chorusing activity was mainly affected by tide level. In contrast, at a deeper location, although tidal currents causes a decrease in calling rate, tide level did not significantly influence calling, and there was a higher calling rate at night. These data show that photoperiod and tide levels can influence broad patterns of Lusitanian toadfish calling activity as in other shallow-water fishes, but fine temporal patterns in acoustic interactions among nesting males is more complex than previously known for fishes.
\end{abstract}

\section{Introduction}

Animals use acoustic signals to convey different types of information, and timing can play a crucial role in communication (Bowling et al., 2013; Ravignani et al., 2014). The temporal organization of acoustic signals has an important role in male-male interactions and mate choice in several taxa (Greenfield and Roizen, 1993; Klump and Gerhardt, 1992; Wilson and Cook, 2016). Several fish species form aggregations during the breeding season and males actively vocalize to attract females (Amorim et al., 2015). In this context, males may show chorusing behaviour by vocalizing at the same periods of the day (Table 1), often restricted by environmental constraints (e.g. tidal rhythms; Table 1).
Choruses may occur in a particular short period of the day (e.g. dawn or dusk) or fish may exhibit calling activity throughout the day and/or night. Some advantages of chorusing behaviour have been proposed, including improvement in detection of suitable breeding areas by conspecifics (e.g. Muller, 1998), enhancement of mate localization (e.g. Wells, 1977), reduction of mate assessment costs and decrease in individual predation risk (e.g. Ryan et al., 1981). The major disadvantages being increased competition and the difficulty to discriminate an individual from its neighbours (Gerhardt and Huber, 2002).

Gregarious vocal fish males may listen to calling neighbours and adjust the timing of their repetitive calls according to social context (mating or male-male competition). But their fine-scale temporal

\footnotetext{
* Corresponding author at: Departamento de Biologia Animal and cE3c, Centre for Ecology, Evolution and Environmental Changes, Faculdade de Ciências, Universidade de Lisboa, Bloco C2. Campo Grande, 1749-016 Lisboa, Portugal.

E-mail address: manuel_1990_v@hotmail.com (M. Vieira).

1 Present address: Departamento de Biologia Animal, Faculdade de Ciências, Universidade de Lisboa, Bloco C2. Campo Grande, 1749-016 Lisboa, Portugal.
} 
patterns of interaction have rarely been addressed in detail (Amorim. et al., 2015). An expected consequence of calling in a chorus is masking (Amorim et al., 2015; Bee et al., 2012). Masking can however be avoided if males alternate vocalizations with their neighbours. Such fine-scale vocal interactions have been shown in several animals (insects: Gerhardt and Huber, 2002; frogs: Dyson and Passmore, 1988; Gerhardt and Huber, 2002; birds: Todt and Naguib, 2000). Vocal interactions can also involve synchrony of acoustic signals (Gerhardt and Huber, 2002; see Table 2 for these and other definitions), that can be used in an agonistic context (fish: Thorson and Fine, 2002; Mensinger, 2014; Staaterman et al., 2018; Salas et al., 2018; birds: Todt and Naguib, 2000). Synchrony is verified when calls overlap more frequently than expected by chance, and alternation when overlap occurs less frequently than expected by chance (Greenfield, 1994). Several types of alternation have been described including antiphony alternation, when the phase offset is $180^{\circ}$ (Ravignani et al., 2014). In some fish species it seems that call overlap is rare (Winn, 1967; Fish, 1972; Thorson and Fine, 2002; Fine and Thorson, 2008; Van Wert and Mensinger, 2019), but the rules underlying fine temporal patterns in chorusing males still need to be ascertained. This is especially interesting because male-male vocal interactions may involve an active adjustment of calling rates to the neighbours' vocal activity, which may be dependent on male condition (Jordão et al., 2012) and motivation (e.g. perceived increase in male competition; Remage-
Healey and Bass, 2005).

The Lusitanian toadfish, Halobatrachus didactylus, is a benthic species with an unusually rich vocal repertoire (Amorim et al., 2008) that produces sounds in both reproductive and agonistic contexts (dos Santos et al., 2000; Vasconcelos et al., 2010). However, the boatwhistle (BW) dominates its vocal activity (Amorim et al., 2006, 2008, 2010b) and is produced in both contexts (Vasconcelos et al., 2010). Like other Batrachoididae species, Lusitanian toadfish territorial males usually nest under rocks and vocalize to attract mates (Amorim et al., 2016; Vasconcelos et al., 2012). This sedentary behaviour provides an opportunity to extract detailed information about their individual calls and interactions in the wild (Fine and Thorson, 2008; Amorim et al., 2016).

Studies on the Lusitanian toadfish revealed adjustment of individual calling rates depending on the social environment (Amorim et al., 2011; Jordão et al., 2012). Males calling alone mostly called at low rates, while chorusing males exhibited higher calling rates and produced longer calls (Amorim et al., 2011; Vasconcelos et al., 2011). Unlike less active vocal nest-holders, males calling at a higher rate than average tended to adjust calling to the neighbours' calling rate (Jordão et al., 2012) pointing to the existence of an interesting chorusing dynamics in this species. Nevertheless, detailed characterization of male-male vocal interactions including fine temporal patterns of call production in relation to social and non-social factors remains to be explored. Previous studies of the

Table 1

Examples of fish chorus daily patterns during the mating season.

\begin{tabular}{|c|c|c|c|c|c|}
\hline Family & Species & $\begin{array}{l}\text { Eggs } \\
\text { type }^{\text {a }}\end{array}$ & Timing & Location & Reference \\
\hline \multirow[t]{10}{*}{ Batrachoididae } & \multirow{2}{*}{$\begin{array}{l}\text { Lusitanian toadfish (Halobatrachus } \\
\text { didactylus) }\end{array}$} & \multirow[t]{2}{*}{$\mathrm{D}$} & & Field (Lisbon, Portugal) & Amorim et al. (2011) \\
\hline & & & $\begin{array}{l}\text { All (highly constrained by tide) } \\
\text { All (more at night) }\end{array}$ & $\begin{array}{ll}\text { Intertidal } & \text { Field (Lisbon, } \\
\text { Subtidal } & \text { Portugal) }\end{array}$ & Present study \\
\hline & \multirow[t]{5}{*}{ Oyster toadfish (Opsanus tau) } & \multirow[t]{5}{*}{$\mathrm{D}$} & All & Field (Maryland, USA) & Fine (1977) \\
\hline & & & All (more at night) & Captivity & $\begin{array}{l}\text { Maruska and Mensinger } \\
\text { (2009) }\end{array}$ \\
\hline & & & All (less at dusk) & Field (South Carolina, USA) & Monczak et al. (2017) \\
\hline & & & $\begin{array}{l}\text { All (some decrease at dawn and } \\
\text { increase at dusk) }\end{array}$ & Field (Maryland, USA) & Ricci et al. (2017) \\
\hline & & & All (more at dusk and night) & Field (Massachusetts, USA) & $\begin{array}{l}\text { Van Wert and Mensinger } \\
\text { (2019) }\end{array}$ \\
\hline & Gulf toadfish (Opsanus beta) & $\mathrm{D}$ & All & Field (Florida, USA) & Breder (1968) \\
\hline & $\begin{array}{l}\text { Three-spined toadfish (Batrachomoeus } \\
\text { trispinosus) }\end{array}$ & $\mathrm{D}$ & Night & Captivity & Rice and Bass (2009) \\
\hline & $\begin{array}{l}\text { Bocon toadfish (Amphichthys } \\
\text { cryptocentrus) }\end{array}$ & $\mathrm{D}$ & Night & Field (Bocas del Toro, Panamá) & Staaterman et al. (2018) \\
\hline \multirow[t]{14}{*}{ Sciaenidae } & \multirow[t]{2}{*}{ Silver perch (Bairdiella chrysoura) } & \multirow[t]{2}{*}{$\mathrm{P}$} & \multirow[t]{2}{*}{ Night (dusk) } & Field (North Carolina, USA) & Luczkovich et al. (2008) \\
\hline & & & & Field (South Carolina, USA) & Monczak et al. (2017) \\
\hline & \multirow[t]{2}{*}{ Weakfish (Cynoscion regalis) } & \multirow[t]{2}{*}{$\mathrm{P}$} & \multirow[t]{2}{*}{ Dusk } & Field (Delaware, USA) & $\begin{array}{l}\text { Connaughton and Taylor } \\
\text { (1995) }\end{array}$ \\
\hline & & & & Field (North Carolina, USA) & Luczkovich et al. (2008) \\
\hline & \multirow[t]{2}{*}{ Red drum (Sciaenops ocellatus) } & \multirow[t]{2}{*}{$\mathrm{P}$} & \multirow[t]{2}{*}{ Dusk } & Field (North Carolina, USA) & Luczkovich et al. (2008) \\
\hline & & & & Field (South Carolina, USA) & Monczak et al. (2017) \\
\hline & \multirow[t]{2}{*}{ Black drum (Pogonias cromis) } & \multirow[t]{2}{*}{$\mathrm{P}$} & \multirow[t]{2}{*}{ Dusk } & Field (Florida, USA) & Locascio and Mann (2011) \\
\hline & & & & Field (South Carolina, USA) & Monczak et al. (2017) \\
\hline & $\begin{array}{l}\text { Whitemouth Croaker (Micropogonias } \\
\text { furnieri) }\end{array}$ & $\mathrm{P}$ & Dawn and Dusk & Field (Pando,Uruguay) & Tellechea et al. (2011) \\
\hline & \multirow[t]{3}{*}{ Spotted seatrout (Cynoscion nebulosus) } & \multirow[t]{3}{*}{$\mathrm{P}$} & \multirow[t]{3}{*}{ Dusk } & Captivity & Montie et al. (2017) \\
\hline & & & & Field (North Carolina, USA & Luczkovich et al. (2008) \\
\hline & & & & Field (South Carolina, USA) & Monczak et al. (2017) \\
\hline & Brown meagre (Sciaena umbra) & $\mathrm{P}$ & Dusk & Field (Corsiga, France) & Parmentier et al. (2017) \\
\hline & Meagre (Argyrosomus regius) & $\mathrm{P}$ & Dusk & Captivity & Vieira et al. (2019) \\
\hline \multirow[t]{2}{*}{ Serranidae } & Goliath grouper (Epinephelus itajara) & $\mathrm{P}$ & Night & Field (Florida, USA) & Mann et al. (2009) \\
\hline & Red hind (Epinephelus guttatus) & $\mathrm{P}$ & Dusk & Field (Puerto Rico, USA) & Mann et al. (2010) \\
\hline Ophidiidae & Cusk-eel (Ophidion rochei) & $\mathrm{P}$ & $\begin{array}{l}\text { Peak at Dusk (some calls throughout } \\
\text { the night) }\end{array}$ & $\begin{array}{l}\text { Field (Gulf of Trieste, Italy) } \\
\text { Field (Corsica, France) }\end{array}$ & $\begin{array}{l}\text { Picciulin et al. (2018) } \\
\text { Kéver et al. (2016) }\end{array}$ \\
\hline Sebastidae & $\begin{array}{l}\text { False kelpfish (Sebastiscus } \\
\text { marmoratus) }\end{array}$ & $\mathrm{V}$ & All (peak at dawn and dusk) & Captivity & $\begin{array}{l}\text { Miyagawa and Takemura } \\
\text { (1986) }\end{array}$ \\
\hline \multirow[t]{2}{*}{ Unknown } & Nine chorus types, of unknow species & - & All, Day, Dusk, or Night & Field (Darwin, Australia) & Parsons et al. (2016) \\
\hline & Five chorus types, of unknow species & - & Dawn, Dusk or Night & Field (Santos Bay, Brazil) & $\begin{array}{l}\text { Sanchez-Gendriz and } \\
\text { Padovese (2017) }\end{array}$ \\
\hline
\end{tabular}

\footnotetext{
${ }^{\text {a }}$ Eggs types were classified as (D) demersal, (P) pelagic or (V) viviparous.
} 

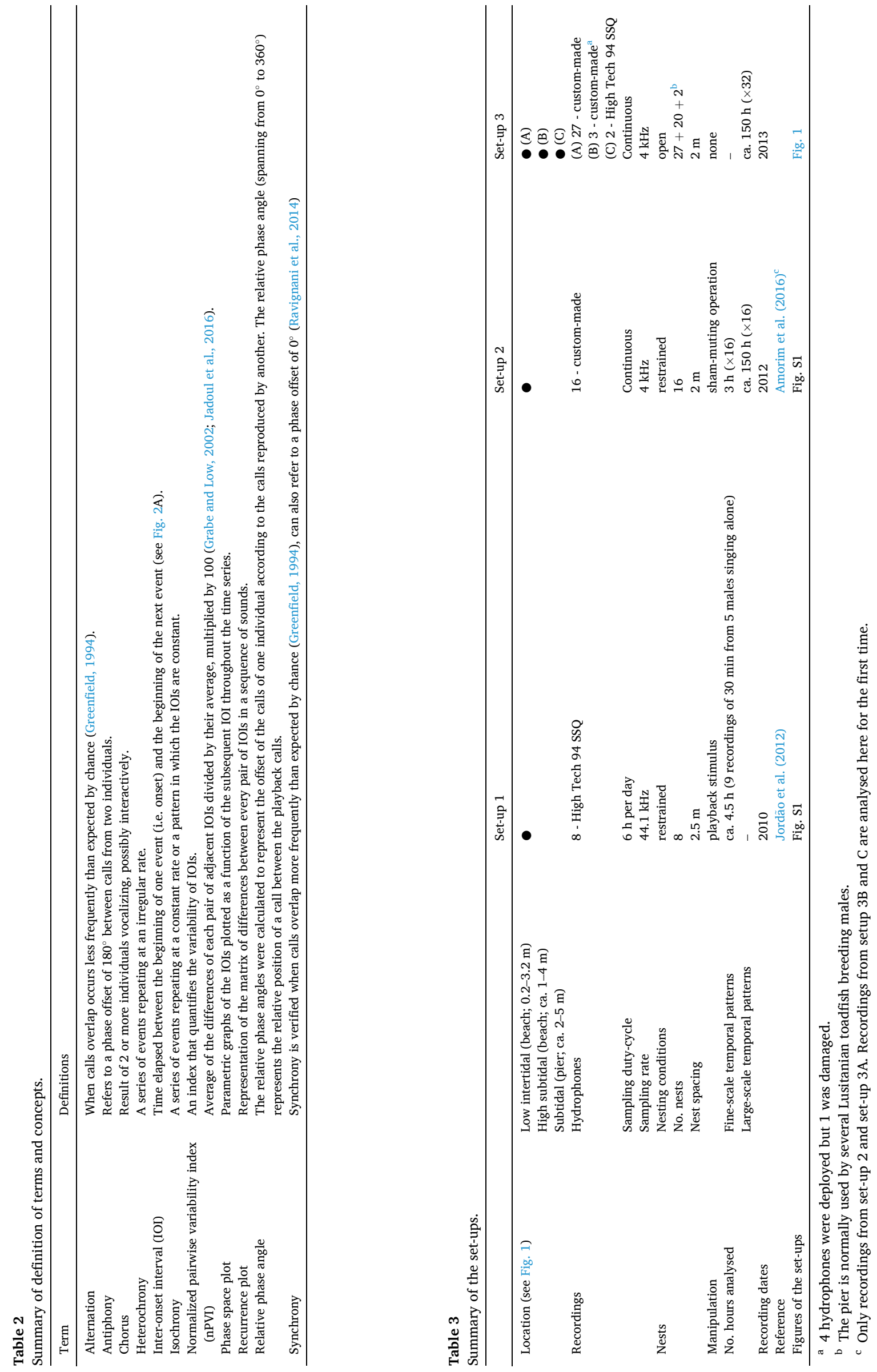


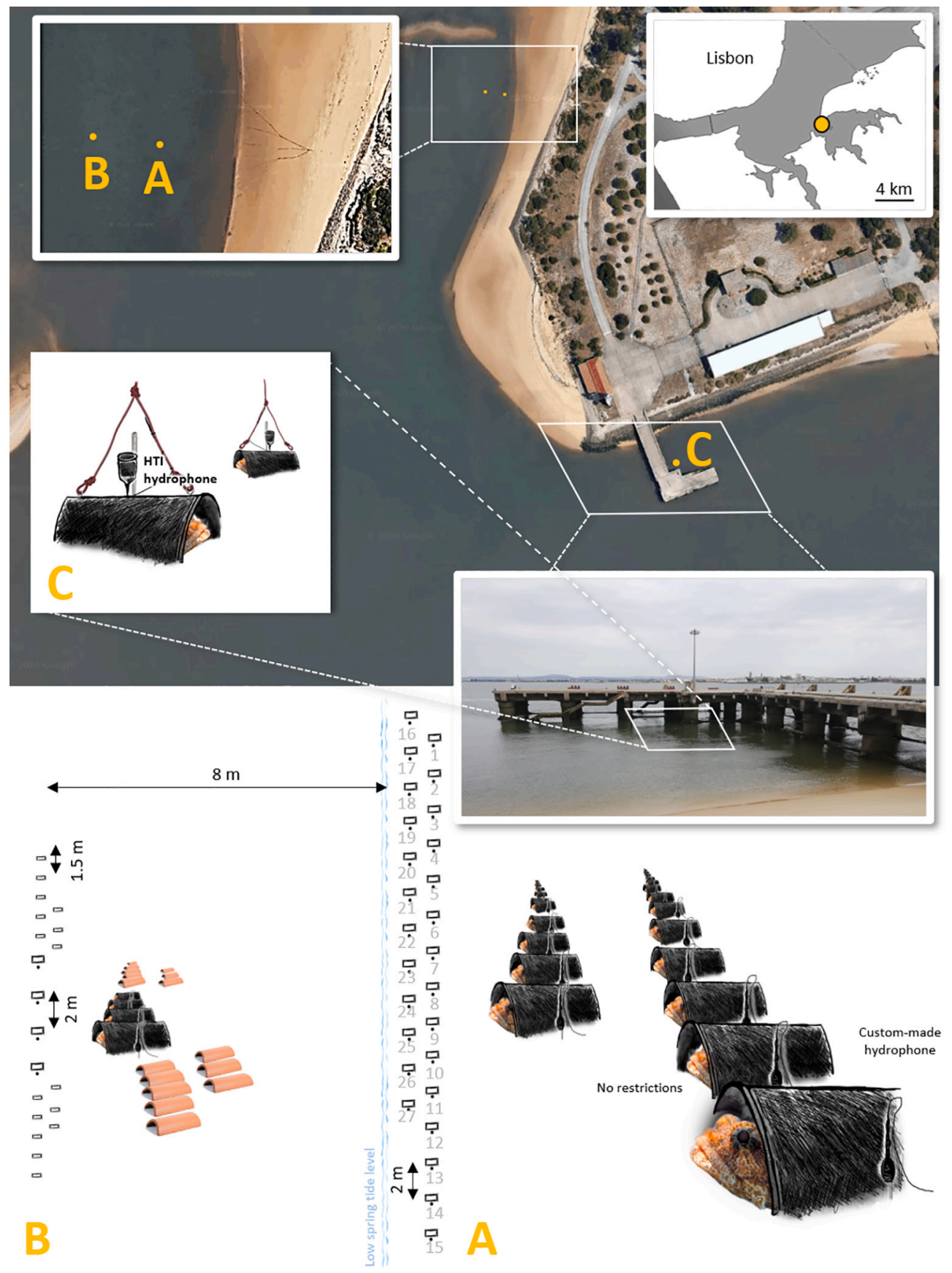

Fig. 1. All the experiments took place in the Tagus estuary (BA6 - Air Force Base no. 6, Montijo, Portugal; $38^{\circ} 42^{\prime} \mathrm{N}, 8^{\circ} 58^{\prime} \mathrm{W}$ ). This figure represents the set-up 3 with deployments in (A) lower intertidal zone (beach; this location is the same for set-up 1, 2 and 3A); (B) Higher subtidal zone (beach; set-up 3B); and (C) Subtidal zone (pier; set-up 3C). Males occupied spontaneously the artificial hemicylinder concrete nests and could move freely throughout the recordings.

Lusitanian toadfish large-scale chorusing rhythms showed that the vocal activity is affected by the fluctuations of tide level at an intertidal zone (Amorim et al., 2011) but how this species behaves in less shallow areas remains unknown.

In the present study we aim to shed light on fine-scale temporal vocal patterns - (1) rhythms of males singing alone and with a conspecific sound playback; (2) patterns of male-male vocal interactions (alternation and synchrony) depending on male distance and motivation (calling rate); and large-scale temporal vocal patterns - (3) daily patterns of vocal activity taking into account the effect of water temperature, tide level, vertical tidal velocity and time of day. To do so we characterized the Lusitanian toadfish vocal temporal patterns during the peak of mating season (May and July; Amorim et al., 2006), when competition for nesting sites and for attracting mates is highest (Amorim et al., 2010a). We investigated the temporal structure of the vocalizations of fish calling alone and analysed the fine temporal-scale of male-male acoustic interactions. Additionally, we compared the large-scale chorusing rhythms of males inhabiting areas of different depths and subjected to the different fluctuations of the physical environment.

\section{Material and methods}

\subsection{General methods}

\subsubsection{Animals and sound recordings}

To describe the temporal patterns of Lusitanian toadfish calling 
activity, several datasets from previously published studies were reanalysed (set-ups summarized in Table 3, see also Fig. 1). Set-up 1: selected recordings of toadfish males calling alone and exposed to playbacks of BWs from other individuals (from Jordão et al., 2012); setup 2: continuous recordings of restrained males in artificial concrete hemicylindrical nests placed in one row parallel to the shoreline, including non-manipulated fish and fish subject to a sham-surgery (i.e., anaesthesia and a small ventral cut followed by one or two stiches, cf. Amorim et al., 2016); and set-up 3: continuous recordings from 32 nests spontaneously occupied by males at three different depths (recordings from males occupying 27 nests at the shallower area on the intertidal zone were also used by Amorim et al., 2016). Recordings from setups 3B and $\mathrm{C}$ are analysed here for the first time. Procedures from previously published studies complied with the Portuguese animal welfare laws, guidelines and policies (Amorim et al., 2016; Jordão et al., 2012). The recordings carried out in setups $3 \mathrm{~B}$ and $\mathrm{C}$ did not involve animal manipulation or experimentation.

All the experiments took place during the Lusitanian toadfish breeding season (May to July) in the Tagus estuary (BA6 - Air Force Base no. 6, Montijo, Portugal; $38^{\circ} 42^{\prime} \mathrm{N}, 8^{\circ} 58^{\prime} \mathrm{W}$; Fig. 1).

2.1.1.1. Set-up 1. Eight artificial hemicylinder concrete nests $(50 \mathrm{~cm}$ long, $30 \mathrm{~cm}$ wide and $20 \mathrm{~cm}$ high) were placed $2.5 \mathrm{~m}$ apart in a row on an intertidal zone at the beach of BA6. Nests were only exposed to air during low spring tides, approximately every fortnight (Figs. 1 and S1). Males spontaneously occupied the nests, and then were restricted by wrapping the nest with a medium-sized grid plastic mesh. A small opening at the front allowed the smaller females to move freely while preventing males from escaping the nest. Several nests had fertilized eggs at the end of the confinement period (Jordão et al., 2012).

Each shelter had a hydrophone positioned $10 \mathrm{~cm}$ from its entrance and from the substrate (High Tech 94 SSQ; High Tech Inc., Gulfport, MS, USA; sensitivity $-165 \mathrm{~dB}$ re. $1 \mathrm{~V} / \mu \mathrm{Pa}$, frequency response within $\pm 1 \mathrm{~dB}$ from $30 \mathrm{~Hz}$ to $6 \mathrm{kHz}$ ). Simultaneous multichannel recordings were made to a laptop connected to USB A/D converter devices (Edirol UA25; Roland, Osaka, Japan; 16 bit, $44.1 \mathrm{kHz}$ acquisition rate per channel) controlled by Adobe Audition 3.0 (Adobe Systems Inc., Mountain View, CA, USA).

Here we used the ca. 30 min recordings previously selected by Jordão et al. (2012), with a fish singing while at least the immediate left and right neighbours were silent. These recordings also included opportunistic 5 min playbacks mimicking a conspecific neighbour calling at two constant rates. The underwater speakers (Electrovoice UW30; Lubell Labs Inc. Columbus, OH, USA; Frequency Response: 0.1-10 $\mathrm{kHz}$ ), were connected to an amplifier (Blaupunkt GTA 260) and fed through the D/A subsystem of an USB Edirol UA25 controlled by Adobe Audition 3.0 (Adobe Systems Inc). The manually adjustable amplification was adjusted according to the tide level since the output of the speakers change with depth. Frequencies below $100 \mathrm{~Hz}$ were not well reproduced due to the speakers' frequency response. Note that the fundamental frequency of a typical Lusitanian toadfish call is ca. $60 \mathrm{~Hz}$., with the dominant frequency usually being the second or fourth harmonic (Amorim et al., 2006). The fundamental frequency of the boatwhistle can also be the one with most energy as reported by Vasconcelos et al. (2010) for agonistic interactions.

2.1.1.2. Set-up 2. Sixteen artificial hemicylinder concrete nests (similar to the ones used in set-up 1) were placed $2 \mathrm{~m}$ apart in a row on an intertidal zone at the beach of BA6, and as above were only exposed to air during low spring tides at approximately every fortnight (Figs. 1 and S1). Subject males were collected from similar nests deployed nearby. As reported by Amorim et al. (2016), fish were randomly assigned to three experimental groups: muted, sham-operated and intact, and restrained in the concrete nests by covering the nest entrance with a stainless steel mesh with an opening in the front only large enough for the females to enter. Muted and sham-operated males were subjected to a surgery where a small incision was made in the abdominal wall; muted males had the swimbladder deflated to prevent sound production while sham males had the swimbladder left intact and were observed to vocalize as intact fish (see Amorim et al., 2016 for details). As in set-up 1 several vocal males had fertilized eggs at the end of the confinement period.

Each of the 16 nests had a custom-made hydrophone positioned next to its midlateral wall at approximately $10 \mathrm{~cm}$ from the substrate. The vocalizations of males were continuously recorded between spring low tides using stand-alone 16 channel dataloggers (LGR-5325, Measurement Computing Corp, Norton, MA, USA; $4 \mathrm{kHz}$ sampling rate, $16 \mathrm{bit}$ ).

A datalogger (HOBO-U20-001-01, Onset Computer Corp., MA, USA) was placed inside a nearby empty nest to measure water temperature and pressure during recordings.

2.1.1.3. Set-up $3 A, B$ and $C$. In the same location of set-up 1 and 2, we deployed 27 artificial concrete nests in two rows, placed $2 \mathrm{~m}$ apart (Fig. 1; set-up 3A). Males spontaneously occupied the nests during the submersion period and could move freely throughout recordings. Every fortnight, when nests were exposed during spring low tides, they were inspected for occupation and the presence of egg clutches (see 'Opennest experiments' in Amorim et al., 2016). As in set-up 1 and 2 several vocal males had fertilized eggs at the end of the period. Depth at this place ranged from 0.2 to $3.2 \mathrm{~m}$.

We deployed four additional artificial concrete nests at ca. $8 \mathrm{~m}$ in front of the 27 nests, $2 \mathrm{~m}$ apart, in a row parallel to the shoreline. Near these four nests, but at least further than $2 \mathrm{~m}$ away, we deployed 16 roof tiles to increase the number of available nests and the chances of having the concrete nests occupied by breeding toadfish males (Fig. 1; set-up 3B). All these nests were in a subtidal area and were always submersed, and never inspected. Depth at this subtidal area ranged from ca. 1 to $4 \mathrm{~m}$. We deployed a custom-made hydrophone positioned next to each of the 31 intertidal and subtidal concrete nests' midlateral wall at approximately $10 \mathrm{~cm}$ from the substrate.

We further deployed 2 hydrophones (High Tech 94 SSQ) next to a nearby pier, each attached to one concrete nest (Fig. 1, set-up 3C). The pier is normally used by Lusitanian toadfish breeding males (Vieira et al., 2020) and meagre (Argyrosomus regius; Pereira et al., 2020). Depth at this place ranged from ca. 2 to $6 \mathrm{~m}$.

We continuously recorded the vocalizations of males using three stand-alone 16 channel dataloggers (two in set-up $3 \mathrm{~A}$ and $\mathrm{B}$, and one in set-up 3C; LGR-5325, Measurement Computing Corp, Norton, MA, USA; $4 \mathrm{kHz}$ sampling rate, $16 \mathrm{bit}$ ).

One temperature and pressure datalogger (HOBO-U20-001-01, Onset Computer Corp., MA, USA) was also placed inside an empty nest near the 27 intertidal nests.

\subsubsection{Automatic recognition of fish vocalizations}

To detect the fish sounds on the recordings we used the automatic recognition system described by Vieira et al. (2015) for call type identification (see Vieira et al., 2015 for the overall flowchart and details of the method). In brief, multiple hidden Markov models HMMs were trained using sounds of each defined category, the recordings being then classified according to the model with the highest likelihood. This process includes the signal processing and the HMM time alignment, followed by an evaluation of the recognition system:

2.1.2.1. Signal processing. The first step in the signal processing is to cut the waveform into a sequence of elementary segments according to a predefined window duration (cf. Fig. 1 in Vieira et al., 2015). We used a window of $32 \mathrm{~ms}$ with a $50 \%$ overlap, and the following acoustic features: cepstrum, Mel-frequency cepstral (MFC), delta, and acceleration coefficients. A Hamming window was applied to each frame. The MFCC used 26 filterbank channels ranging from 20 to $1000 \mathrm{~Hz}$. Only the first 12 cepstral coefficients were selected, including the range of frequencies 
most audible of the boatwhistles produced by this species (from the fundamental frequency up to the 5th harmonic), and excluding sounds from other species (e.g. meagre) that might interfere.

2.1.2.2. HMM time alignment. We created a 14 state model to classify the BWs. As in Vieira et al. (2015), we added models with 5 states for modelling double-croaks, croaks, background noise (silence), nonbiological sound patterns with high energy and short duration (e.g., consecutive non-biological pulses with high energy), and also a model with 7 states for modelling grunt trains. These additional states were crucial to avoid misclassification of BWs but were not used to count those sound types due to their rarity and the low accuracy of recognition (as reported in Vieira et al., 2015).

The automatic HMM-based recognition system was prepared to recognize BWs, taking into account the existence of other sounds produced by this species and abiotic noises. For each sound type, a representative subset of samples was used to train the HMMs. The training set used to produce the recognition system included 35 BWs with high signal-to-noise ratio of several datasets and 76 sounds for the other models (15 double-croaks, 13 croaks, 16 grunt trains and 32 nonbiological sounds). The transition probabilities and the elementary segment probability densities of each state were estimated with the Baum-Welch algorithm (Baum et al., 1970).

In the recognition phase, each sound type was matched against the estimated HMM for each sound type. This was achieved by using a Viterbi algorithm (Forney, 1973) that produced a likelihood measure for each HMM.

For computations we used the HMM Toolkit (HTK, University of Cambridge, UK), a group of modules written in $\mathrm{C}$ to create automatic recognition systems for human speech (Young et al., 2006).

2.1.2.3. Evaluation of the recognition system. The number of substitution errors (i.e., when one signal type is recognized as another signal type, $\mathrm{S}$ ), deletion errors (i.e., when a sound type occurs but is not detected by the system-a false negative, D), insertion errors (i.e., when a signal is detected by the system but it did not occur-a false positive, I) and the total number of labels in the reference transcriptions $(\mathrm{N})$ were determined (Young et al., 2006). Only the call of interest was evaluated, i.e. the BWs. The performance of the recognition systems was then evaluated by computing the percentage of correctly recognized BWs (identification rate) using:

Identification rate $(\%)=\frac{\mathrm{N}-\mathrm{D}-\mathrm{S}}{\mathrm{N}} \times 100$,

or by computing the recognition accuracy using:

Accuracy $(\%)=\frac{\mathrm{N}-\mathrm{D}-\mathrm{S}-\mathrm{I}}{\mathrm{N}} \times 100$.

To evaluate the output of the recognition system its identification rate and accuracy were assessed by comparison with manually annotated data on a subsample of $15 \mathrm{~min}$ of each hydrophone of set-up 3A, and $30 \mathrm{~min}$ for set-up $3 \mathrm{~B}$ and $3 \mathrm{C}$. The performance on these datasets was similar to the ones observed in Vieira et al. (2015).

To avoid the detection of calls at more than one hydrophone, the system was created using BWs with high signal-to-noise ratio, which consequently lead to ignore most of the low signal-to-noise ratio BWs (ca. $<10 \mathrm{~dB}$ ). Consequently, these calls with low signal-to-noise ratio were considered as insertions in this evaluation. Nevertheless, approximately $99 \%$ of BWs in the acoustic data were recognized correctly.

At set-up 3A, we obtained an identification rate of $95.7 \%$, accuracy of $65.7 \%$, and a false positive rate of $23.1 \%$. The lower accuracy value mostly represents the recognition of sounds produced by the closest neighbours' males (mostly sounds with a SNR near $10 \mathrm{~dB}$ considered in the manual annotation). At set-up 3B, an identification rate of $100 \%$, accuracy of $52.2 \%$, and a false positive rate of $32.3 \%$ were observed. In set-up 3B, we deployed 16 roof tiles to increase the number of available nests, most false positives are from BW produced by males nested on those roof tiles. At set-up 3C, the identification rate reached the $94.9 \%$, and we obtained an accuracy of $89.2 \%$, and a false positive rate of $5.4 \%$. The pier (set-up 3C) is normally used by Lusitanian toadfish breeding males, and the males that occupied the space between both hydrophones were detected by both.

For the analysis of interactions with vocalizing conspecifics or with playbacks (set-up 1 and 2), labels were manually corrected by visual inspection using the software Wavesurfer (Medina and Solorio, 2006).

\subsection{Fine-scale temporal patterns}

The computations using the sounds' labels and all statistics were made in $\mathrm{R}$ (R Core Team, 2018).

\subsubsection{Rhythms of males singing alone and with conspecific sound playback}

We extracted the sound labels for nine 30-min recordings from the 2008 dataset (from 5 calling males; Set-up 1; Table 3). Inter-onset intervals (IOIs) and relative phase angles were computed. The IOI is the interval between the beginning of one event and the beginning of the consecutive event; in this case between calls of the same individual. The relative phase angles were calculated to represent the offset of the calls of one male according to the calls reproduced by the UW-30 speaker. The relative phase angle (spanning from $0^{\circ}$ to $360^{\circ}$ ) represents the relative position of a call between the playback calls. Synchrony is represented by a relative phase angle of $0^{\circ}$, and antiphony alternation by a relative phase angle of $180^{\circ}$ (Ravignani et al., 2014). Because in several cases the IOI differed greatly between the vocalizing fish and the playback (e.g. the fish called more often than the playback), the phase offset for all the calls produced between two consecutive BW playbacks were accounted and represented with different colours. Rayleigh's uniformity tests were performed to assess the non-uniformity of the phase angles (Tauber, 2001).

Recurrence and phase space plots were used to visualize rhythmic structural regularities in IOIs (Ravignani and Norton, 2017). Recurrence plots are a powerful tool to observe patterns in a time series (Eckmann et al., 1987), and represent the matrix of differences between every pair of IOIs in a sequence of sounds. Both axes represent the IOI in their original sequential order. Here, black squares represent pairs of IOIs whose difference is below $0.3 \mathrm{~s}$. Phase space plots represented here are parametric graphs of the IOIs, plotted as a function of the subsequent IOI throughout the time series. Phase-space plots are a very useful visualization tool and can be employed as an assumption-free diagnostic to analyse rhythms (Ravignani, 2017). The normalized pairwise variability index (nPVI) was also calculated for each recording (Grabe and Low, 2002; Jadoul et al., 2016). The nPVI is the average of the differences of each pair of adjacent IOIs divided by their average, multiplied by 100 . This index is an indicator of rhythmicity that quantifies the variability of IOIs. It decreases with an increase in the regularity of IOIs and reaches zero with a perfect isochronous rhythm (isochrony can be defined as temporal patterns in which the time interval between the onset of consecutive events are equal or multiple of the unit interval). The nPVI ranges between 0 and 200 (Condit-Schultz, 2019), from isochronous (usually lower than ca. 10; Ravignani, 2017; Schneider and Mercado III, 2019), to heterochronous rhythms in a variety of nPVI values depending on the complexity of the rhythm (Condit-Schultz, 2019; Ravignani, 2017; Schneider and Mercado III, 2019) and random patterns (Ravignani, 2017 reported values of ca. 90).

\subsubsection{Patterns of male-male vocal interactions}

To describe male-male acoustic interactions, automatic annotations of 3 periods of $1 \mathrm{~h}$ of synchronized recordings from 16 nests/hydrophones were manually inspected (i.e. $16 \times 3 \mathrm{~h}$ ). These recordings included calls produced by each of the 16 nest-holders and were chosen from one day of June 2012 where males exhibited a higher calling rate 
(set-up 2; Table 3). Relative phase angles were computed to represent the phase offset of the calls of each pair of individuals and depicted as rose-plots. Each rose-plot represents the distribution of the relative phase angles (spanning from $0^{\circ}$ to $360^{\circ}$ ), i.e. the relative position of a call in respect to the neighbour's calls. Each male-male interaction was classified by the distance between the two calling males. After preliminary visualization of the rose-plots produced by each pair, we decided to aggregate the phase angles according to distance between males - separated by $\leq 5 \mathrm{~m}$ or $>5 \mathrm{~m}$, since in more distant pairs phase angles consistently presented a higher variability (see examples in Fig. S2). The distance threshold was selected in accordance with the communication active space reported for the Lusitanian toadfish by Alves et al. (2016) that estimated maximum distance with correct perception of conspecific's BWs to be from 5 up to $13 \mathrm{~m}$, using BWs recorded during nearly high tide (water levels 2.2-2.6 m). The dividing distance of $5 \mathrm{~m}$ (the lower range of found correct perception distance) was chosen as BW propagation is highly depth dependent (Alves et al., 2016). To extract the relevant interactions among fish while using the pool of calls produced by the 16 fish, we only considered the occurrences when a single male's BW was between the BWs of another male. Note that preliminary rose plots were obtained for each pair of individuals considering all the phase angles (examples represented in Fig. S2). Although some differences are observed, the general distribution of phase angles was maintained, and this choice simplified the interpretation of the phase angle distribution. Furthermore, a high number of phase angles was still considered. We used circular statistics (Batschelet, 1981) to calculate the angular means. Rayleigh's uniformity tests were performed to test the non-uniformity of the considered phase angles (Tauber, 2001) to investigate whether the calls' interactions were systematically in synchrony or alternation.

Furthermore, for each individual singing on each of the 3 periods of $1 \mathrm{~h}$ analysed (Table 3 ), we performed a cross-overlapping analysis as schemed in Fig. 3 for each calling male. From the original recording $(0 \mathrm{~s}$ lag) and using a window time step of $0.2 \mathrm{~s}$ up to $\pm 10 \mathrm{~s}$, we counted the percentage of calls overlapping more than $0.1 \mathrm{~s}$ with the calls of the others fish taken as reference for each time lag. This allowed to understand if the observed interactions are a consequence of a continuous adjustment of the timing of the calls throughout the bout or a consequence of fish isochronous calling causing, by chance, many alternations or overlaps (as hypothesised by Winn, 1967 for Opsanus tau). We classified each male by their calling activity (lower or higher calling rate than $9 \mathrm{BW} \mathrm{min}^{-1}$ ) and the BW overlaps by the distance between each pair of calling males ( $\leq 5 \mathrm{~m}$ and $>5 \mathrm{~m}$ ). The cut point on calling activity followed Amorim et al. (2011) and represent the reported population average ( $\left.8.8 \mathrm{BW} \min ^{-1}, n=576\right)$. This analysis will investigate if interaction patterns differ with male distance and motivation (calling rate).

These analyses were conducted in $\mathrm{R}$, requiring the 'circular' library for circular statistics.

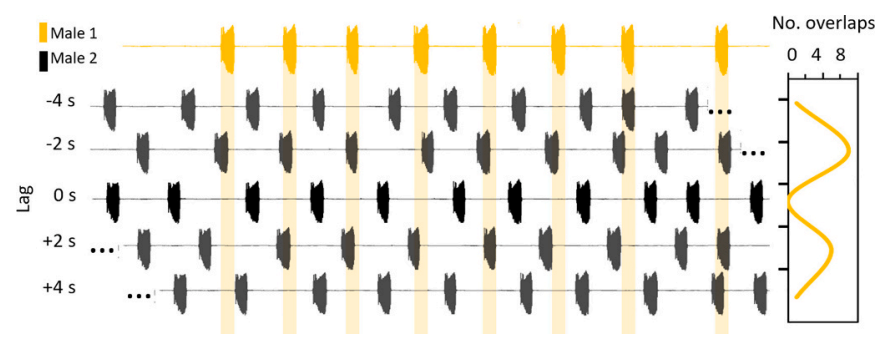

Fig. 2. Representation of how the cross-overlapping analysis was processed for each calling male. From the original recording ( $0 \mathrm{~s}$ lag) and using a window time step, we counted the percentage of calls overlapping with the calls of other fish (BWs in yellow) for each time lag. (For interpretation of the references to colour in this figure legend, the reader is referred to the web version of this article.)

\subsection{Large-scale temporal patterns}

\subsubsection{Daily patterns of vocal activity}

The number of BWs present in the recordings was obtained from the automatic recognition system described before. We counted the number of calls per hour in round-the-clock recordings on the three locations (Fig. 1; set-up 2 and set-ups 3A, 3B and 3C) from ca. 6 days from July 2013 and ca. 6 days from July 2012 (Table 3). Generalized Additive Models (GAM) were used to test the effect of temperature, tide level, vertical tidal velocity and time of day on the calling activity at each location. Note that tidal vertical velocity is the time derivative of tide level. GAMs were chosen because preliminary analysis of the time-series indicated non-linear relationships (Hastie and Tibshirani, 1990; Wood, 2017). Thin plate regression splines were used, and all terms were subject to the second-order penalty. The interactions of the covariates analysed were taken into account with tensor products interactions (Wood, 2006). These interactions terms were only retained when they were assessed to be significantly different from a zero (flat) function. Smoothness parameters were chosen using restricted maximum likelihood selection. Due to the positive over-dispersion observed, all models used a negative binomial distribution and identity link function. This statistical analysis was conducted in R using the 'mgcv' library.

\section{Results}

\subsection{Fine-scale temporal patterns}

3.1.1. Rhythms of males singing alone and with conspecific sound playback The patterns of fish calling alone in four recordings of 30-min are depicted in Fig. 3C (see summary of set-up 1 in Table 3). The recurrence plots and phase space plots show changes in the IOIs (scheme in Fig. 3A; and the respective calling rate) throughout the recordings indicating a high inter- and intra-individual variability (Fig. 3C). The four recurrence plots (Fig. 3C, upper panels) exhibit several darker regions that correspond to almost perfect isochronous rhythms. These almost isochronous segments match with periods of higher calling rate. A recurrence plot and phase space plot of a 5-min playback is represented in Fig. 3B to exemplify an almost perfectly annotated isochronous sequence of $20 \mathrm{BW}$ $\min ^{-1}$

To depict patterns in more detail, Fig. 3D shows a subsection of 60 IOIs from the previous plots. Subsections of fish 1.6 and 2.3 show clearly an almost perfect isochronous rhythm (both with nPVI of ca. 10-11). Between these more uniform subsections (cf. darker squares in Fig. 3C upper panels), several less rhythmic sequences were observed (lighter regions in the same plots, and a good example in the subsection of fish 1.3 in Fig. 3D, $3^{\text {rd }}$ plot, with $\mathrm{nPVI}=18$ ). Some recordings exhibit a more aperiodic rhythmicity (cf. subset of fish 1.3 in Fig. 2D, $2^{\text {nd }}$ plot, with $\mathrm{nPVI}=35$ ). Notice, however, that even in these subsets exhibiting a more aperiodic pattern, several sequences of 2-4 BWs with similar IOIs were present (groups of black squares). Globally, and considering these 30 min examples, fish 1.6 had the lower variance of IOIs, with a nPVI of 13.4. Fish 2.6 presented an intermediate nPVI of 23.1, while fish 1.3 had the larger nPVI of 32.4 and 26.5. On all 9 recordings analysed, the nPVI ranged from 13.4 to 47.3 (mean $\pm \mathrm{SD}, 31.2 \pm 10.3$ ). The playbacks had low values of nPVI $(3.4 \pm 2.3)$ as expected.

Phase plots can create geometric regularities caused by the representation of rhythmic IOIs taking into account the sequential structure of the sounds (Ravignani, 2017), but no clear geometrical regularities are present on any of the toadfish plots (Fig. 3C, D). The triangular-like pattern observed is possibly a consequence of the fish recurrent alternation between 2 and 3 calls with lower IOIs and 1-2 calls with higher IOIs. This was clear during the preliminary visual inspection of the recordings, especially on fish with a lower calling rate.

How do fish react to conspecific's call BW playback? Blue bars on both axis of the recurrence plots represent the presence of playbacks (Fig. 3C). Usually a change on the IOIs is coincidental with the beginning 
A

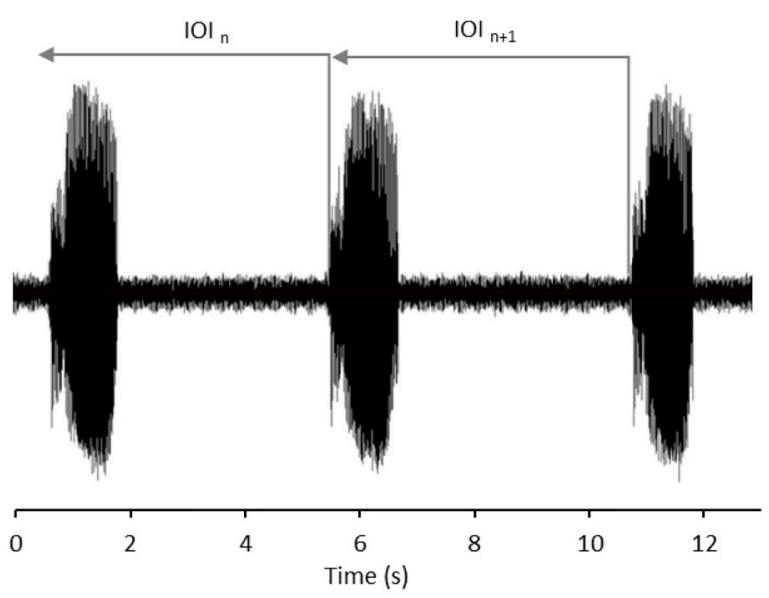

C
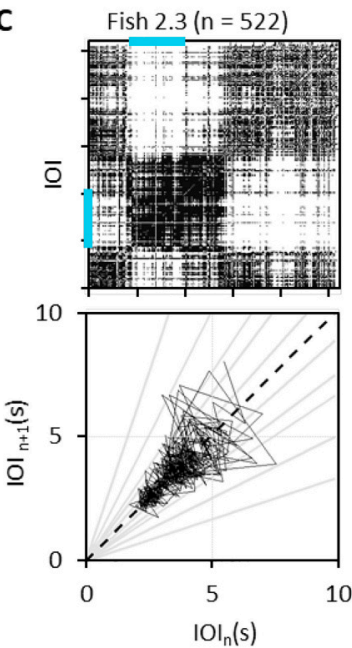

Fish $2.3(n=60)$
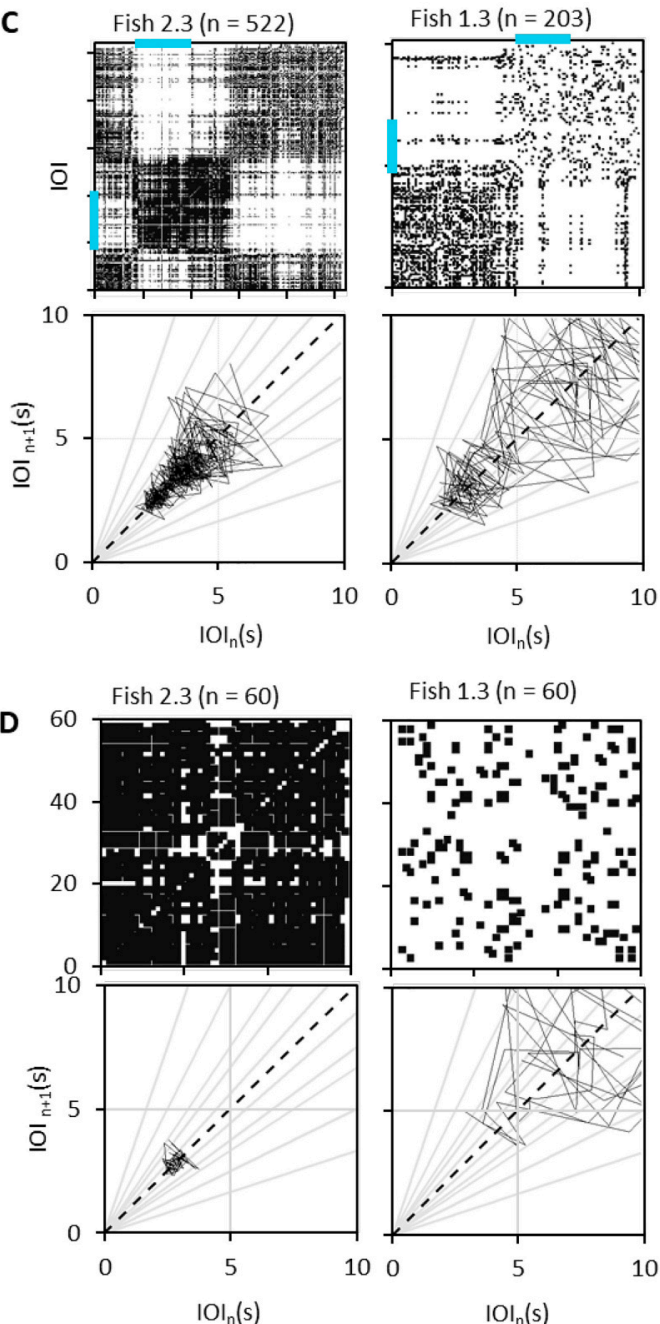

$\mathrm{IOI}_{\mathrm{n}}(\mathrm{s})$

Fish $1.3(n=60)$
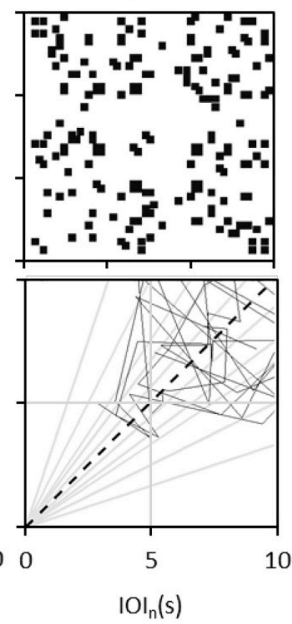
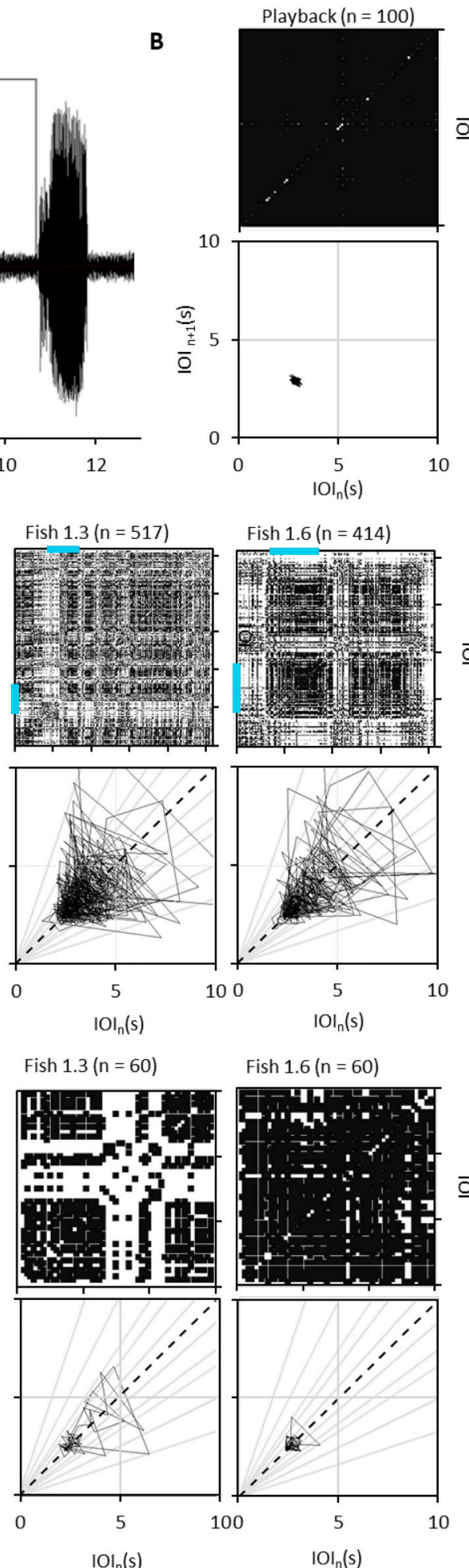

Fish $1.6(n=60)$
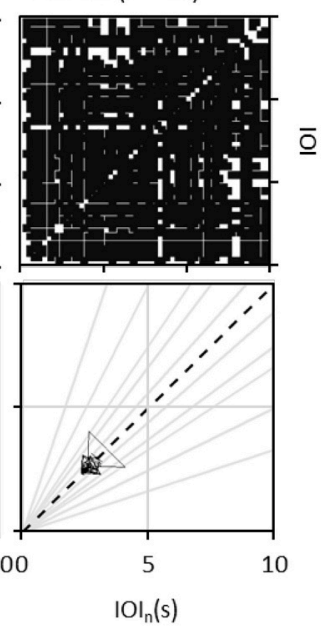

Fig. 3. Rhythms of males singing alone and playback interference. (A) Represent the Inter-onset interval (IOI) calculated for each call. (B) Recurrence and phase space plots - (top and bottom respectively) of an almost perfect isochronous playback with $20 \mathrm{BW}$ $\min ^{-1}$. Black squares represent pairs of IOIs whose difference is below 0.3 s. (C) Paired plots of recurrence and phase space for four 30 -recordings of males singing alone: $1^{\text {st }}$ and $2^{\text {nd }}$ columns are fish exposed to a 5 -min playback with $5 \mathrm{BW} \min ^{-1}$ and 3rd and 4th columns are fish exposed to $20 \mathrm{BW}$ $\min ^{-1}$. Blue bars in the recurrence plots represent the period of playback exposure. (D) Subsections of 60 IOIs from the 30-min recordings represented above. Phase plots' grey ratio lines represent the following ratios of IOIs: $3: 1,2: 1,3: 2,4: 3,9: 8,1: 1$, and their reciprocals. Name of each fish are as reported by Jordão et al. (2012). These plots show the changes in the IOIs throughout the recordings and indicate a high inter- and intra-individual variability. Several periods of almost perfect isochronous rhythms (black areas in recurrence plots) occur usually at lowers IOIs (lower variability at lower IOIs in phase plots). Shifts during the playback can be observed in the recurrence plots. (For interpretation of the references to colour in this figure legend, the reader is referred to the web version of this article.) of the conspecific playback sounds $\left(1^{\text {st }}, 2^{\text {nd }}\right.$ and $4^{\text {th }}$ plot on Fig. 3C). Some fish changed the calling rate but maintained an almost isochronous rhythm ( $1^{\text {st }}$ plot on Fig. $3 \mathrm{C}$ ). Others progressed from a more aperiodic pattern to an almost isochronous rhythm ( $4^{\text {th }}$ plot on Fig. $3 \mathrm{C}$ ) while others showed the reverse (2nd plot on Fig. 3C). In one situation, we also observed a shift only after some minutes of playback (3rd plot on Fig. 3C).

Relative phase angles of fish calls were calculated against the play-

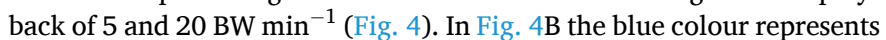

the phase of the first BW produced after each BW played back. If more than one call was produced between consecutive BWs in the playback, the phase angles of the subsequent calls were represented in grey (Fig. 4B). In the $5 \mathrm{BW} \mathrm{min}^{-1}$ playback, the periodicity of BWs' phase angles point to a uniform distribution of phase angles (Rayleigh Test of Uniformity for all the relative phase angles represented in Fig. $4 \mathrm{~B}$ in blue and grey, $p$-value $=0.24, n=305$ ), suggesting that the males are not adjusting the timing of their calls to the PBK. However, the $1^{\text {st }}$ call produced after each playback had a mean phase angle of $71^{\circ}$ (Rayleigh 
A

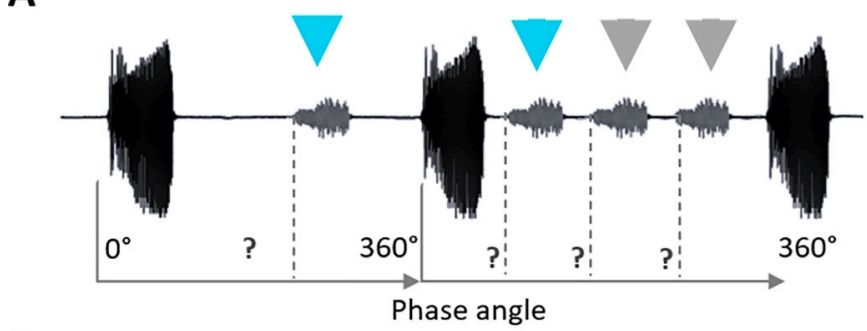

B

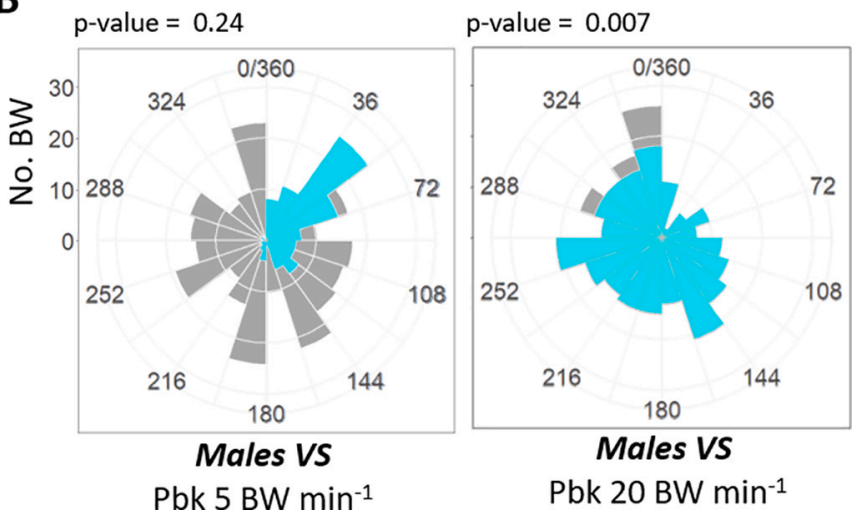

Fig. 4. Males interactions with isochronous playbacks. (A) Representation of how the relative phase angles were calculated; Calls with lower amplitude represent a calling male and calls with higher amplitude represent the playback. (B) Rose plots of the relative phase angles distribution on all recordings exposed to each playback (5 males exposed to a $5 \mathrm{BW} \mathrm{min}^{-1}$ playback and 4 males exposed to a $20 \mathrm{BW} \mathrm{min}^{-1}$ playback). We considered all the BWs produced by a male in between the playback: blue represents the first BW produced by the male after the playback, and the subsequent BWs are represented in grey. In the $5 \mathrm{BW}$ min-1 playback, the uniform distribution of the phase angles suggest that the males are not adjusting the timing of their calls to the playback. However, the $1^{\text {st }}$ call produced after each playback had a mean phase angle of $71^{\circ}$ with notably less events under $36^{\circ}$. In the $20 \mathrm{BW}$ min- 1 playback, the distribution of phase angles was not uniform mostly due to the lack of calls under $100^{\circ}$. Both distributions indicate a possible avoidance of the playback call. $p$-values refer to the Rayleigh's uniformity test. (For interpretation of the references to colour in this figure legend, the reader is referred to the web version of this article.)

Test of Uniformity, $p$-value $<0.001, n=102$; see blue phase angles in Fig. 4B, left panel) with notably less events under $36^{\circ}$, which could indicate that fish are paying attention to and avoiding the neighbour's vocalizations (in this case the playback). Notice that low relative phase angles for the $1^{\text {st }}$ call produced after each playback are expected on a situation where fish calling rate is exceedingly higher than the playback.

In the experiments with $20 \mathrm{BW} \mathrm{m^{-1 }}$ playback, the distribution of phase angles was not uniform (Rayleigh Test of Uniformity, $p$-value $=$ $0.007, n=279$ ), mostly due to the lack of calls under $100^{\circ}$, indicating avoidance of the playback call. Between c. $100^{\circ}$ and $360^{\circ}$ no clear preferential phase angle was observed. In addition, almost no cases with more than one call produced by the fish between consecutive BWs in the playback were observed ( $n=14$; see blue phase angles in Fig. 4B, right panel).

In short, rhythms of males singing alone presented a high between and within individual variability, usually showing higher regularity when calling at a higher rate. Additionally, fish changed calling rhythms in the presence of playback and exhibited a possible avoidance.

\subsubsection{Patterns of male-male vocal interactions}

Fig. 5A shows an example of types of male-male interactions observed throughout the preliminary analysis of the recordings. From the synchronized round-the-clock multi-channel recordings, 3 periods of $1 \mathrm{~h}$ were selected. In these recordings we detected a total of $3462 \mathrm{BWs}$ produced at $3 \mathrm{am}, 3849 \mathrm{BWs}$ at $9 \mathrm{am}$, and $2427 \mathrm{BWs}$ at $16 \mathrm{pm}$, from 16 males.

In the recordings at $3 \mathrm{am}, 15$ males were active but mostly with a low calling rate (mean $\pm \mathrm{SD}$, range: $3.9 \pm 2.8,0.4-8.5 \mathrm{BW} \mathrm{min}^{-1}$ ). The rose plots of close-by individuals $(\leq 5 \mathrm{~m})$ show a high incidence of relative phase angles between $342^{\circ}$ and $18^{\circ}$, with a mean of $7.2^{\circ}$ (Fig. 5E). The Rayleigh test of uniformity with unspecified mean direction confirmed a non-uniform distribution observed ( $\mathrm{z}=0.37, p<0.001, n=1487)$. A Rayleigh test with specified mean $\left(\mu=0^{\circ}\right)$ further suggests a nonuniform distribution consistent with synchrony of BWs between these males at close distances $(\mathrm{z}=0.37, p<0.001)$. An example of synchronous interactions is depicted in Fig. S2. Fig. S2 shows rose-plots of relative phase angles between male 13 and male 14 at this hour (males were $2 \mathrm{~m}$ apart). Fig. 5D represents an example of the temporal structures observed at this hour. Most calling males showed high irregularity and multiple transitions between low and high IOIs. This irregularity was translated in higher nPVI values $(29.2 \pm 87.8$ at 3 am vs. $19.6 \pm$ 51.5 at 9 am and $21.9 \pm 118.5$ at $16 \mathrm{pm}$ ). The relative phase angles of BWs produced by more spaced males ( $>5 \mathrm{~m}$ ) were more uniformly distributed (Fig. 5E). At $3 \mathrm{am}$, the Rayleigh test of uniformity with unspecified mean direction confirmed the uniform distribution ( $3 \mathrm{am:} \mathrm{z}=$ $0.003, p=0.96, n=5405$ ). These results point to synchronous interactions in these low activity males but only when in close range $(\leq 5$ $\mathrm{m})$.

In the other $2 \mathrm{~h}$ analysed, 9 and 12 males were vocally active at 9 am and $16 \mathrm{pm}$, respectively, but only 5 had a calling rate higher than $9 \mathrm{BW}$ $\min ^{-1}$ ( 3 males at $9 \mathrm{am}: 6.4 \pm 5.8 \mathrm{BW} \mathrm{min}{ }^{-1}$, ranging from 2.2 to 15.7

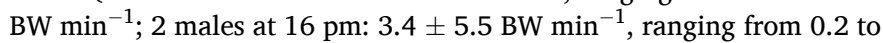

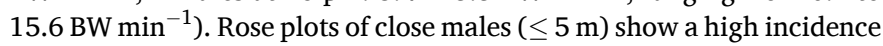
between $100^{\circ}$ and $250^{\circ}$ (Fig. 5E; only 9 am is represented), and a mean angle close to $180^{\circ}$. Several BWs between $342^{\circ}$ and $18^{\circ}$ (overlaps) are also observed. An example of mostly alternation with some synchrony between male 13 and male 14 at 9 am (males $2 \mathrm{~m}$ apart) is given in Fig. S2. The Rayleigh test of uniformity with unspecified mean direction confirmed a non-uniform distribution of phase-angles ( $9 \mathrm{am:} \mathrm{z}=0.40, p$ $<0.001, n=3662 ; 16 \mathrm{pm:} \mathrm{z}=0.21, p<0.001, n=876$ ). A Rayleigh test with specified mean $\left(\mu=180^{\circ}\right)$ confirms a distribution consistent with males alternating BWs when at close distances ( 9 am: $\mathrm{z}=0.28, p<$ $0.001 ; 16 \mathrm{pm}: \mathrm{z}=0.14, p<0.001$ ). In spaced males $(>5 \mathrm{~m}$ ), although the distribution is wider, the presence of more interactions with phase angles between $80^{\circ}$ and $260^{\circ}$ still translates into a rejection of the uniform distribution ( $9 \mathrm{am}$ : mean $=180^{\circ}, \mathrm{z}=0.16, p<0.001, n=5573 ; 16$ pm: mean $\left.=177^{\circ}, \mathrm{z}=0.14, p<0.001, n=2196\right)$. A Rayleigh test with specified mean of $180^{\circ}$ is still significant on both hours ( 9 am: $\mathrm{z}=0.09$, $p<0.001 ; 16 \mathrm{pm:} \mathrm{z}=0.07, p<0.001$ ). These results point to mostly alternation interactions in these periods, specially when in close range $(\leq 5 \mathrm{~m})$.

The cross-overlapping (Fig. 6) shows that in fish with high calling

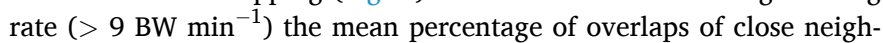
bours $(\leq 5 \mathrm{~m}$ ) increase greatly at a lag of $\pm 2 \mathrm{~s}$ pointing to a possible tendency for a fixed delay. On fish with lower calling rate, the maximum percentage of overlaps is observed on the lag zero (true overlap of BWs). The absence of a cyclic periodicity suggest that the BW interactions observed for close neighbours are adjusted continuously throughout the bout. Between neighbours at larger distances, the cross-overlapping presents a mean percentage of overlaps consistently higher. The absence of a well-defined peak between neighbours at larger distances suggests that the observed overlaps may be a result of chance.

In summary, we observed two types of male-male interactions (synchrony and alternation). Synchrony was more common for individuals with lower mean calling rate and with a more irregular rhythm. Alternation dominated when individuals presented higher calling rate and a more isochronous rhythm. Both types of interactions 
A

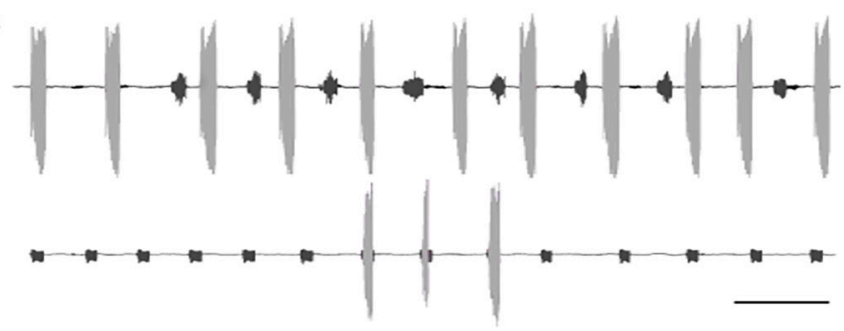

fish 16 at 9 am

C

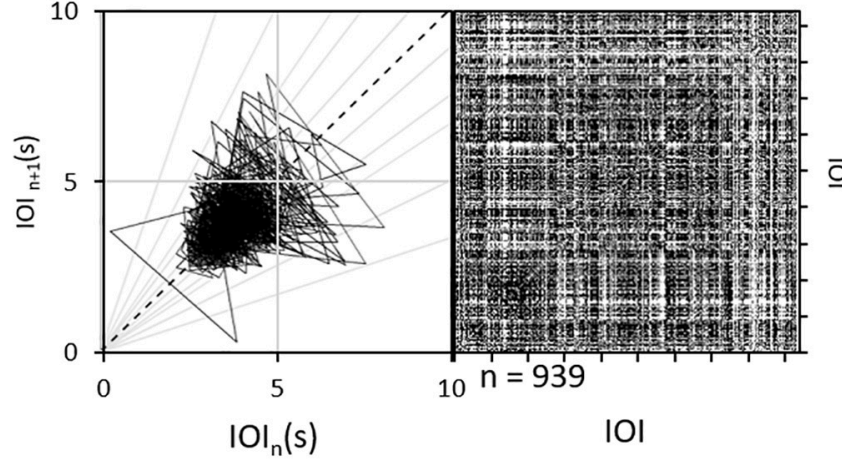

$\leq 5 \mathrm{~m}$

E

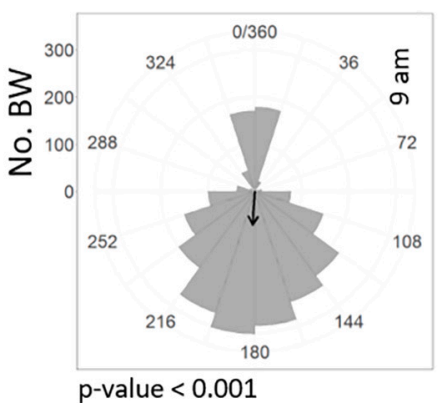

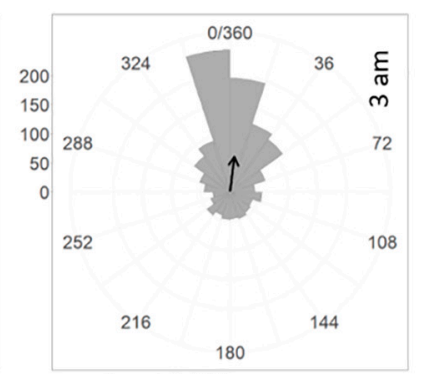

p-value $<0.001$
B

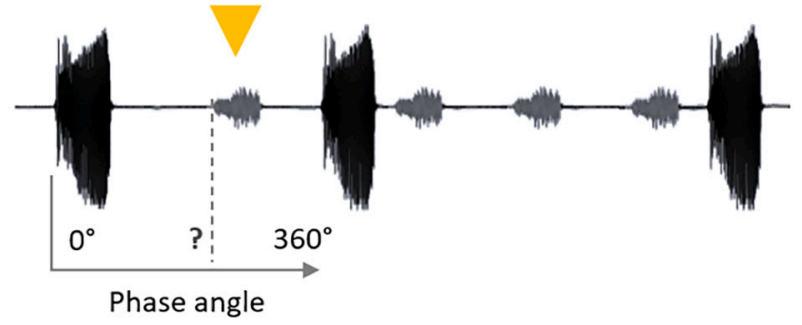

Fig. 5. Male-male interactions. (A) Examples of the most common interactions observed: alternation and synchrony; lighter grey is the male closer to the hydrophone and the black scale-bar represent $5 \mathrm{~s}$. (B) Graphic representation of phase angles considered on (E): only single BWs produced by a male between the BWs of another male were considered. Call with higher amplitude is from the male closer to the hydrophone. (C,D) Paired plots of phase space and recurrence for the same male in two 1 h-recordings at 9 am and 3 am to exemplify the observed rhythms. (E) Rose circular plots of the phase angles between pairs of calling males recorded simultaneously using 16 hydrophones at 2 periods -9 am and $3 \mathrm{am}$. Light grey represents males separated by $5 \mathrm{~m}$ or less, and dark grey, males separated by more than $5 \mathrm{~m}$. Angular mean vectors are represented by an arrow on each plot. $p$-values refer to the Rayleigh's uniformity test. (For interpretation of the references to colour in this figure legend, the reader is referred to the web version of this article.)

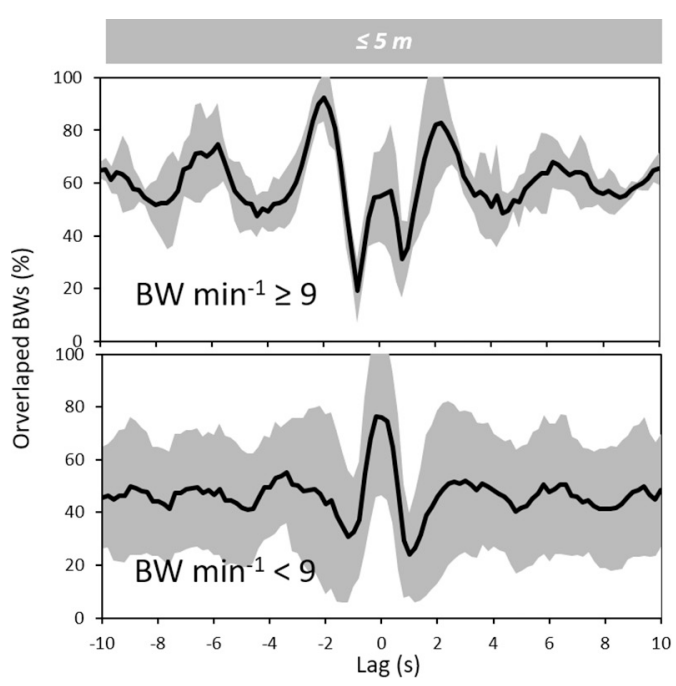

Fig. 6. Cross-overlapping in male-male interactions. See Fig. 2 for a schematic drawing on how cross-overlapping was calculated. Each plot shows the percentage of overlaps calculated for each lag. To observe changes with calling rate and distance, males were classified with high (BW $\min ^{-1} \geq 9$ ) or low mean calling rate $\left(\mathrm{BW} \mathrm{min}^{-1}<9\right.$ ), and by the distance between each pair: $\leq 5 \mathrm{~m}$ (light grey) and $>5 \mathrm{~m}$ (dark grey). The patterns depicted in close-range $(\leq 5 \mathrm{~m})$ neighbours point to synchrony in animals calling at a lower rate and alternation in animals calling at a higher rate. 


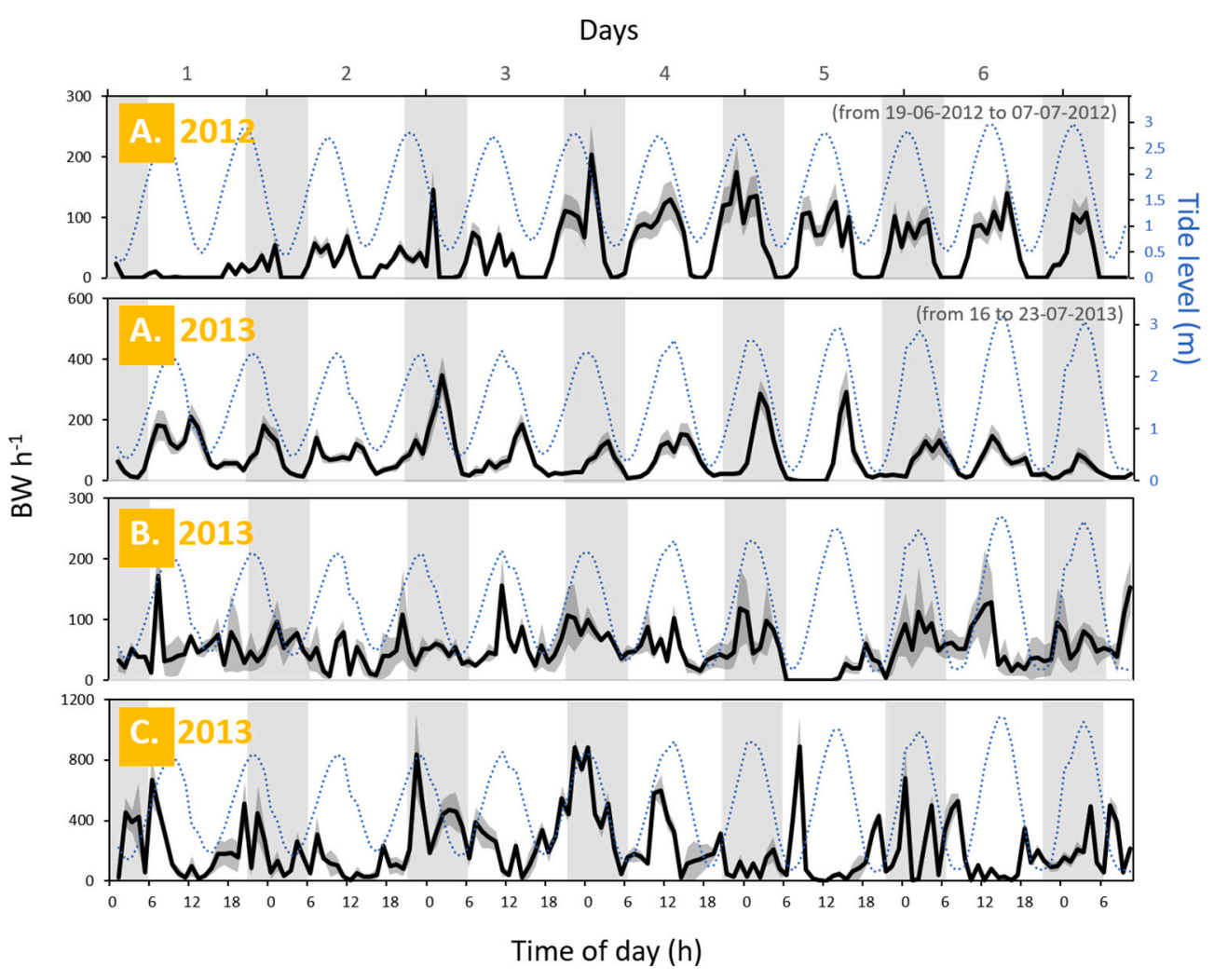

Fig. 7. Daily variation of calling rate (BW $\mathrm{h}^{-1}$ ) at 3 locations at different depths. Letters represented each location: (A) Low intertidal (beach) from 2012 (set-up 2) and 2013 (setup 3A); (B) High subtidal (beach; set-up 3B); and (C) Subtidal (pier; set-up 3C). Solid black line depicts mean number calls counted per hour on several hydrophones (see Table 3 for details), and grey shading the standard error. Notice that the vertical axes are in different scales. Dashed blue line represent the variation of the tide level measured only in the low intertidal zone. Night periods are indicated in light grey. On the intertidal zone the calling activity follows the variations of the tide. At the deeper locations there are no clear patterns. (For interpretation of the references to colour in this figure legend, the reader is referred to the web version of this article.) were clear at close distances $(\leq 5 \mathrm{~m})$, but less evident at larger distances $(>5 \mathrm{~m}$ ). The cross-overlapping function was not cyclic suggesting that neighbours are adjusting the timing of calling in relation to their neighbour's continuously throughout the bout.

\subsection{Large-scale temporal patterns}

\subsubsection{Daily patterns of vocal activity}

From the analysis of ca. 6 days from July 2013, 304,161 BWs were identified in the lower intertidal zone (set-up 3A in Fig. 1; 27 hydrophones), 24,192 BWs in the higher subtidal zone (set-up 3B in Fig. 1; 3 hydrophones), and 66,610 BWs at the deeper location recorded (set-up $3 \mathrm{C}$ in Fig. 1; 2 hydrophones). Note that, even ignoring most calls with a signal-to-noise ratio under ca. $10 \mathrm{~dB}$, the recognition system still detected the same calls at more than one hydrophone. We also included into this analysis 6 days from July 2012 from the intertidal zone, with 103,444 accounted BWs (set-up 2, Fig. S1; 16 hydrophones).

Calling activity was significantly affected by the tide level on the intertidal zone (Figs. 7A and 8A; Table 4). Although the nests were always underwater (minimum water level: $18 \mathrm{~cm}$ ), GAM's indicate an increase of fish vocal activity with tide level $(p<0.001)$, especially at the ebb tide ( $p<0.001$; cf. tidal velocity in Fig. 8). The temperature, ranging about $6{ }^{\circ} \mathrm{C}\left(20.6-26.9{ }^{\circ} \mathrm{C}\right)$, always peaking during the day, presented a significant effect $(p<0.001)$. However, the oberved trend suggests a possible artefact related to the timing of the high tide in the sampled days. No pattern related to the time of day was observed.

In the higher subtidal zone (Figs. $7 \mathrm{~B}$ and $8 \mathrm{~B}$; Table 4), calling activity slightly increased with tide level $(p=0.03)$, but tide phase did not affect calling activity $(p=0.62$ ). Water temperature did not have a significant effect on call activity even as a single explanatory variable in the models. These data revealed a flat relationship between calling rate and time of day.

At the deeper location (Figs. 7C and 8C; Table 4) no significant effects of the temperature or tide level were observed. The tide velocity appears to negatively affect the calling rate, with males producing more BWs at the peak of the tides $(p<0.001)$. Calling rate significantly decreased during the day, showing a non-linear relation with time of day $(p<0.001)$.

In summary, tide greatly constrained the calling activity in the intertidal zone, whereas in the deeper location we observe lower calling activity during the day (set-up 3C). Nevertheless, the variables included in the model explained a low percentage of the variability, specially at both deeper locations (Table 4).

\section{Discussion}

This study investigated the presence of fine and large-scale vocal temporal patterns in wild Lusitanian toadfish males. We recorded these fish during the spawning season at the Tagus estuary (Portugal), annotated their most common call (the boatwhistle, BW) with the support of an automatic call recognition methodology based on the hidden Markov model, and extracted temporal information of nesting males' calling activity. Datasets like the one presented here are a rare opportunity to explore large- and fine-scale calling patterns such as calling rhythms and male-male acoustic interactions.

\subsection{Fine-scale temporal patterns}

Lusitanian toadfish, as many other soniferous gregarious fish species (examples in Table 1), produce sequences of the same call in a repetitive manner. Although we know that sound production is crucial for mating (Amorim et al., 2016; Vasconcelos et al., 2012), fine-scale temporal patterns were never analysed in detail. Here we analysed temporal structures of the BWs produced by Lusitanian toadfish males during the mating season, using visualization methods reviewed by Ravignani and Norton (2017), such as IOIs recurrence plots and IOIs phase space plots. 

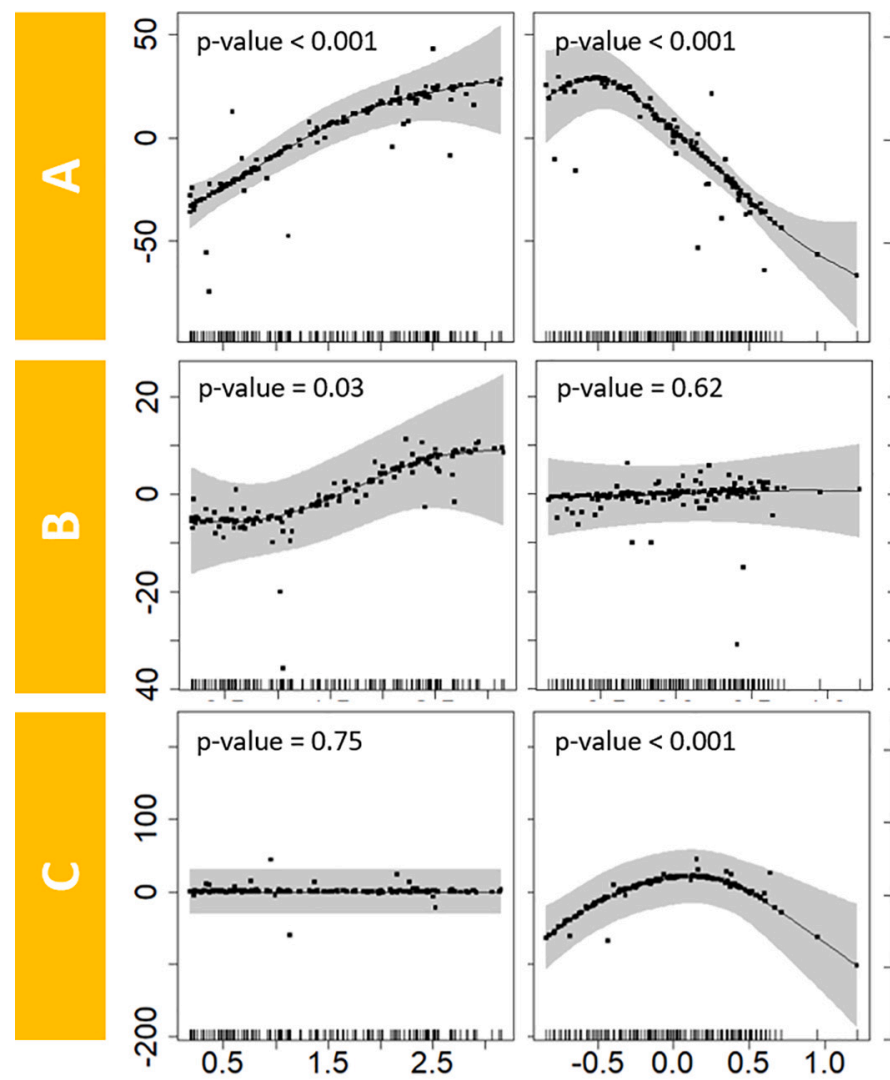

Tide level $(\mathrm{m})$

\section{Tidal velocity $\left(\mathrm{mh}^{-1}\right)$}
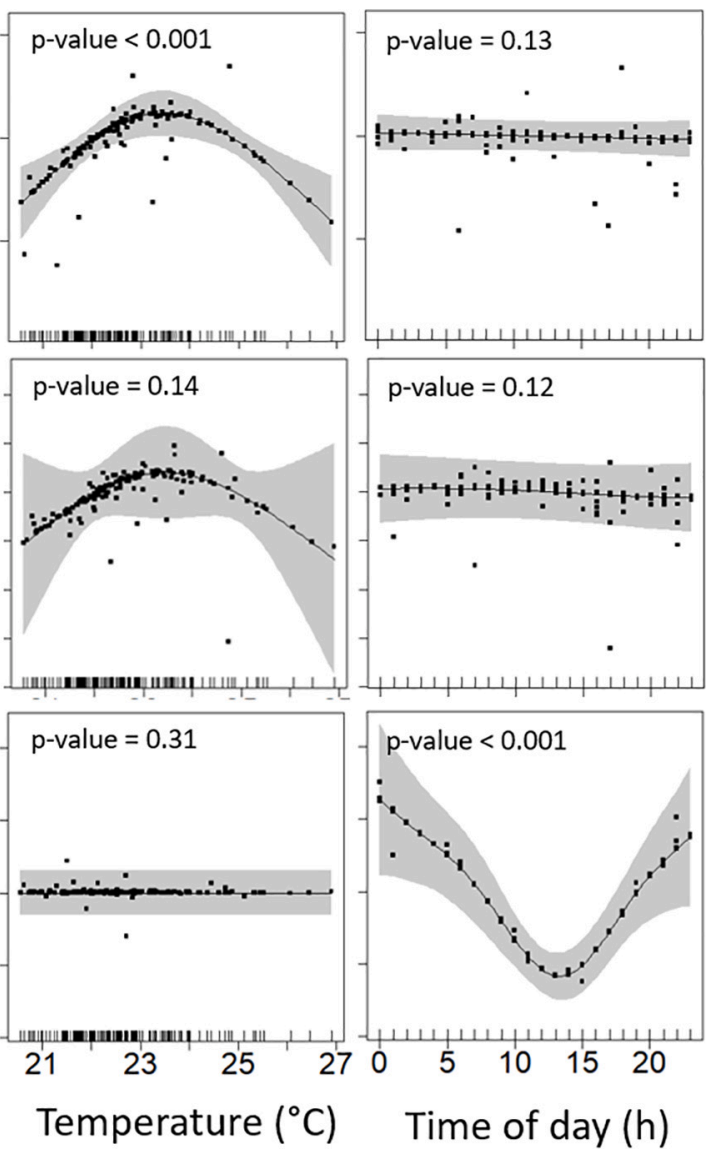

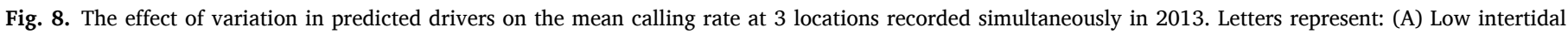

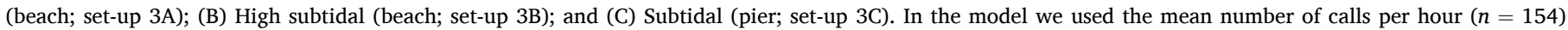

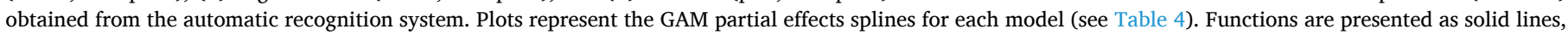

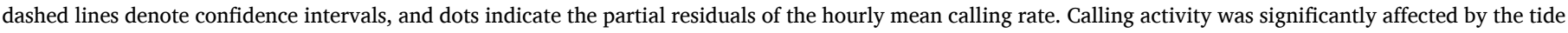

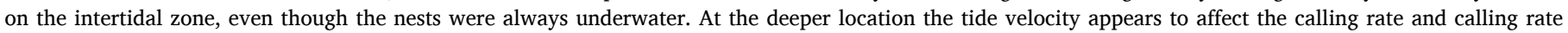
decreases during the day.

We show that Lusitanian toadfish males can exhibit high variability between and within individuals, varying from an almost isochronous to an apparent aperiodic rhythm. Furthermore, males are aware of the neighbours calling activity (as suggested by Jordão et al., 2012), continually adjusting the timing of the vocalizations and interacting through alternation or synchrony, dependent on distance and calling rate.

\subsubsection{Rhythms of males singing alone and with conspecific sound playback}

When males were singing alone, the temporal patterns of BW emission were quite variable between and within individuals. Recurrence plots showed several shifts through each recording indicating recurrent changes in rhythm and/or calling rate. Jordão et al. (2012) previously reported that Lusitanian toadfish males are aware of neighbours' vocal activity, adjusting the calling rate accordingly. Using recordings from the same dataset but using a visualization method based on recurrent plots, we confirmed such conclusion by observing that the rhythm transition was coincident with the beginning of the playback, demonstrating that fish are vigilant and can react quickly to vocalizing conspecifics. However, other transitions occurred without a clear reason. Some individuals showed alternation between almost isochronous calling activity (with nPVI of ca. 10, and higher calling rate) and more aperiodic vocal patterns (with nPVI up to 50 and lower calling rate). Such periods of temporal stability exhibiting a fast almost isochronous rhythm are likely short because they should be harder to endure. Indeed,
Amorim et al. (2010b) found that only Lusitanian toadfish males with a high body condition (higher energetic reserves) can sustain high calling rates that appear to be associated with isochrony. This feature may be used by females to infer male quality as sustained high calling rate is associated with higher reproductive success in this species (Amorim et al., 2016, Vasconcelos et al., 2012) and in other taxa (Byers et al., 2010; de Kort et al., 2009). As in seals (Ravignani et al., 2019), Lusitanian toadfish's phase space plots show the presence of some rhythmic structure, but less stereotyped than the observed in birds and other mammals (birds: Norton and Scharff, 2016; whales: Schneider and Mercado III, 2019; Human: Ravignani, 2017). In the Lusitanian toadfish, 3-4 edges geometrical shapes appear recurrently in several phase space plots suggesting a recurrent intercalation between shorter and longer IOIs. The presence of different rhythms and the transitions between them are also observed in whales and birds, where the temporal structure appears to be related to physiological constraints or social context (Cholewiak, 2008; Mercado III and Handel, 2012; Norton and Scharff, 2016; Schneider and Mercado III, 2019). Further work should deepen into the possible rhythm subsections in Lusitanian toadfish calling activity and its relations with physiological constraints or social context. Furthermore, the measurement and visualization of these temporal rhythms should be optimized to analyse long-term data (e.g. use the annotations of automatic recognition system to assess mean phase angles and nPVI throughout the recording) as its assessment could help to monitor male quality and infer fitness. 
Table 4

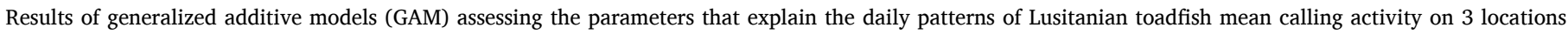
recorded simultaneously.

\begin{tabular}{|c|c|c|c|c|c|c|}
\hline & A.13 & & B.13 & & C.13 & \\
\hline $\mathrm{n}$ & 154 & & 154 & & 154 & \\
\hline$r^{2}$ & 0.46 & & 0.18 & & 0.16 & \\
\hline Deviance explained & $63 \%$ & & $25.2 \%$ & & $26.7 \%$ & \\
\hline Predictor spline & EDF & p-value & EDF & p-value & EDF & p-value \\
\hline Tide level (m) & 1.8 & $<0.001$ & 1.4 & 0.03 & 0.007 & 0.75 \\
\hline Tidal velocity $\left(\mathrm{mh}^{-1}\right)$ & 3.0 & $<0.001$ & 0.3 & 0.62 & 2 & 0.001 \\
\hline Time of day (hour) & 0.2 & 0.12 & 0.2 & 0.12 & 3.4 & $<0.001$ \\
\hline Temperature $\left({ }^{\circ} \mathrm{C}\right)$ & 0.9 & $<0.001$ & 0.7 & 0.14 & 0.0003 & 0.31 \\
\hline Tensor product interactions & EDF & p-value & EDF & p-value & EDF & p-value \\
\hline Temperature $\times$ Tide level & 3.9 & $<0.001$ & 3.5 & $<0.001$ & 1.3 & 0.001 \\
\hline Temperature $\times$ Tide level variation & 2.0 & $<0.001$ & - & - & - & - \\
\hline Temperature $\times$ Time of day & 1.6 & $<0.001$ & 2.2 & 0.09 & 1.0 & 0.007 \\
\hline Tide level $\times$ Time of day & 0.7 & 0.003 & 2.6 & 0.002 & - & - \\
\hline Tide level variation $\times$ Time of day & 1.0 & 0.08 & 2.1 & 0.002 & - & - \\
\hline
\end{tabular}

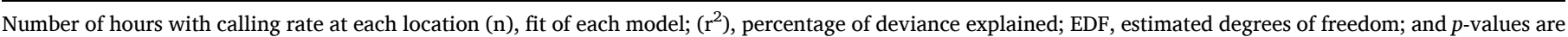
represented. In bold $p$-value lower than 0.05 .

\subsubsection{Patterns of male-male vocal interactions}

We observed two types of male-male interactions: synchrony and alternation. When in a chorus, we show that vocalizing toadfish males are aware of the calling activity of conspecific neighbours and can alternate or synchronise their calls with other fish calls. We observed that close neighbours $(\leq 5 \mathrm{~m})$ tend to sing with a mean phase offset close to $180^{\circ}$ (antiphony alternation) or $0^{\circ}$ (synchrony), probably depending on context (advertisement or agonistic). This interaction pattern was less clear at larger distances when BWs tend to attenuate to background levels. The $5 \mathrm{~m}$ distance threshold used here is consistent with the estimated communication range of up to $5-13 \mathrm{~m}$ in the shallow water breeding area of the Tagus estuary (Alves et al., 2016).

Alternation reduces masking, and thus could facilitate male assessment by the approaching females (Wiley, 1983). The avoidance of superimposing calls with the vocalizations of conspecifics is probably common in fish (Amorim et al., 2015), the low number of references are probably consequence of the lack of analysis of fine-scale interactions in fish. Even though, Winn (1967) considered that the call alternation observed in the oyster toadfish (Opsanus tau) should not differ from what is expected by chance. Recently Van Wert and Mensinger (2019) suggested that males of that species may monitor conspecific vocalizations because less than $1 \%$ of the BWs overlapped with other callers (but no formal analysis was presented). Consistently, the cross-overlapping analysis carried out in our study (Fig. 6) did not show several peaks that could corroborate an alternation or synchrony by chance alone on highly isochronous bouts. Instead it showed a curve that indicates that close neighbours continuously adjust the timing throughout the bout. Several alternation interactions are described for non-fish species. For example Cooley and Marshall (2001) observed quick sequential 'wingflick' female-male interactions in choruses of periodical cidadas, and Ravignani (2019) showed that the seal pup adjusted its calls' onset to occur at a fraction of the playback previous period, showing a relativephase antisynchrony. Lusitanian toadfish males appear to have a more opportunistic strategy. Although in many situations the Lusitanian toadfish appears to have a locked offset approaching $180^{\circ}$, in several circumstances they produced more than one call between the calls of the 'rival' (or playback; Fig. 4B). Furthermore, with the playbacks with higher calling rate analysed in this work the interaction pattern was more uniform, even though the playback amplitude mimicked close neighbours. These results appear to be consistent with interactions between individuals separated by larger distances. Notice however that the loudspeakers used by Jordão et al. (2012) did not reproduce well frequencies below $100 \mathrm{~Hz}$ (Fonseca and Alves, 2012), thus simulating a stronger attenuation of the fundamental frequency of boatwhistles with distance (Alves et al., 2016; Amorim and Vasconcelos, 2008; Vasconcelos et al., 2010). Further experiments with playbacks at different amplitudes and simulating different levels of frequency attenuation should be made to further investigate the males' interaction behaviour.

In the Lusitanian toadfish, it seems that BW synchronization could be used in agonistic context. According to Vasconcelos et al. (2010), BWs can also be used in agonistic contexts, being produced with lower dominant frequency and lower calling rate. In our analysis we observed synchrony interactions in individuals with lower calling rate suggesting they could represent male-male competing interactions. Furthermore, it appears that when males produce these calls with high percentage of overlaps (cf. Fig. 6B) they are usually produced in short bouts (i.e. there is an intercalation between low IOIs and very hight IOIs, see Fig. 4A and D) consistent with being produced during agonistic encounters (Vasconcelos et al., 2010). In other toadfish species several studies have reported the synchronization of short agonistic grunt calls with the neighbour's BW advertisement call (termed acoustic tagging; Thorson and Fine, 2002, Mensinger, 2014; Staaterman et al., 2018; Salas et al., 2018). This seems to be an overspread pattern as other non-fish species also can use call synchronization in agonistic context to disturb rivals (birds: Todt and Naguib, 2000; insects: Cooley and Marshall, 2001).

\subsection{Large-scale temporal patterns}

\subsubsection{Daily patterns of vocal activity}

Besides the social environment, other factors also influence the Lusitanian toadfish calling patterns. We showed that low tide level significantly decreased the calling rate at shallower areas (cf. Fig. 7A and A). This is consistent with Amorim et al. (2011) that showed a significant effect of the tide level on the Lusitanian toadfish males' calling rate in the intertidal zone. Here we also addressed the overall call rate of males that inhabit deeper areas, and therefore are less subject to the harsh fluctuating physical environment of the intertidal zone. On the deeper area, calling rate could not be explained by the tide level and only showed a slight preference for the peak of the tides (periods with lower water flow). Consequently, the decrease in calling rate at shallower waters may be due to the harsher currents and breaking surface waves, and not to endogenous activity rhythms as suggested by Gibson (1982). Furthermore, it is relevant to notice that the attenuation of low frequency sounds is highly dependent on the water level (Mann, 2006; see Alves et al., 2016 for attenuation of BWs), being highly attenuated during low tides in the intertidal zone. This attenuation reduces the communication space and the chance of a calling male being detected by neighbouring males and females (Alves et al., 2016; Fine and Lenhardt, 1983; Mann, 2006). Note, however, that there are several limitations in trying to determine the drivers of the calling rate using three sampling sites and no replicas. Further work should investigate deeper into these observed differences. 
At the deeper location, we observed some decrease in calling activity during day (set-up 3C), consistent with the diel cycles reported for the oyster toadfish (Maruska and Mensinger, 2009; Monczak et al., 2017; Phillips and Swears, 1981; Ricci et al., 2017). This shift suggests that this species might adapt its activity according to the surroundings. Furthermore, the lower activity includes the period that coincide with the presence of the meagre (Argyrosomus regius) chorus (Vieira et al., 2019; Pereira et al., 2020). As meagre sounds were only registered on the deeper location, future work should deepen into the possible temporal partitioning of the acoustic space by these two species (Ruppé et al., 2015).

The absence of a strongly synchronized chorus on a shorter period of time, contrasts with observations in species with pelagic eggs, that usually restrict the calling activity to a well-defined time of day, usually dawn or dusk (Table 1). Choruses and mass spawning at dusk or dawn is likely an adaptation to limit the predation on pelagic eggs (Ferraro, 1980; Hobson and Chess, 1978; Holt et al., 1985; Lobel, 1978). The absence of a well-defined diel rhythm in toadfish species is possibly explained by their reproductive tactics. Usually a female attaches demersal eggs to the nest's ceiling to be cared by the male. Moreover, the arrival of females could possibly explain several peaks of calling activity unexplained by the tide, time of day and temperature. Future work should address how the presence of females change the calling rate of Lusitanian toadfish males, although this is difficult to study in the field when the waters are murky, such as in the present study location.

\section{Conclusion}

In conclusion, Lusitanian toadfish males while in a chorus appear to be aware of the neighbours calling activity, adjusting their vocalizations and interacting through alternation or synchrony, possibly dependent on advertisement or agonistic contest, respectively. Fine-scale temporal patterns may be a good proxy of male condition in fish that could be used by the females for mate selection and have implications on fish fitness. On a larger temporal scale, although tide level constrains the calling rate at shallower waters, in deeper water the environmental conditions do not appear to restrict acoustic activity and only explain a low percentage of the variability. The apparent complexity of the vocal interactions among individuals, and the unexplained rhythm transitions on short recordings, suggest that the overall calling rate of the chorus might be dependent on the social interactions between males (e.g. dear enemy effects, Leiser, 2003) and between males and females. Future experiments should focus on a more detailed analysis considering simultaneous acoustic and video recordings that may allow to relate fine-scale behavioural temporal patterns with territorial behaviour and reproductive success.

\section{Funding sources}

This study was funded by the Fundação para a Ciência e a Tecnologia, Portugal [grant SFRH/BD/115562/2016 to M.V.; strategic projects UID/MAR/04292/2019 to M.C.P.A. by MARE and UID/BIA/00329/ 2019 to P.J.F. by cE3c].

\section{Declaration of Competing Interest}

None.

\section{Acknowledgements}

We are grateful to André Matos, Andreia Ramos, Carlotta Conti, Daniel Alves, Joana Amado, Joana Jordão, Joana R. Vicente, José Lino Costa, Pedro Félix, Raquel Vasconcelos, Rita Carriço and Silvia Pedroso for the valuable assistance. We also thank the Air Force Base No. 6 of Montijo (Portugal) for allowing the field work to collect the recordings analysed in this study.

\section{Appendix A. Supplementary data}

Supplementary data to this article can be found online at https://doi. org/10.1016/j.ecoinf.2021.101281.

\section{References}

Alves, D., Amorim, M.C.P., Fonseca, P.J., 2016. Assessing acoustic communication active space in the Lusitanian toadfish. J. Exp. Biol. 219 (8), 1122-1129.

Amorim, M.C.P., Vasconcelos, R.O., 2008. Variability in the mating calls of the Lusitanian toadfish Halobatrachus didactylus: cues for potential individual recognition. J. Fish Biol. 73 (6), 1267-1283.

Amorim, M.C.P., Vasconcelos, R.O., Marques, J.F., Almada, F., 2006. Seasonal variation of sound production in the Lusitanian toadfish Halobatrachus didactylus. Journal of Fish Biology 69 (6), 1892-1899.

Amorim, M.C.P., Simões, J.M., Fonseca, P.J., 2008. Acoustic communication in the Lusitanian toadfish, Halobatrachus didactylus: evidence for an unusual large vocal repertoire. J. Mar. Biol. Assoc. U. K. 88 (5), 1069-1073.

Amorim, M.C.P., Simões, J.M., Fonseca, P.J., Almada, V.C., 2010a. Patterns of shelter usage and social aggregation by the vocal Lusitanian toadfish. Mar. Biol. 157 (3), 495-503.

Amorim, M.C.P., Simões, J.M., Mendonça, N., Bandarra, N.M., Almada, V.C., Fonseca, P. J., 2010b. Lusitanian toadfish song reflects male quality. J. Exp. Biol. 213 (17), 2997-3004.

Amorim, M.C.P., Simões, J.M., Almada, V.C., Fonseca, P.J., 2011. Stereotypy and variation of the mating call in the Lusitanian toadfish, Halobatrachus didactylus. Behav. Ecol. Sociobiol. 65 (4), 707-716.

Amorim, M.C.P., Vasconcelos, R.O., Fonseca, P.J., 2015. Fish sounds and mate choice. In: Sound Communication in Fishes. Springer, Vienna, pp. 1-33.

Amorim, M.C.P., Conti, C., Sousa-Santos, C., Novais, B., Gouveia, M.D., Vicente, J.R., Modesto, T., Gonçalves, A., Fonseca, P.J., 2016. Reproductive success in the Lusitanian toadfish: influence of calling activity, male quality and experimental design. Physiol. Behav. 155, 17-24.

Batschelet, E., 1981. Circular Statistics in Biology. Academic Press, London.

Baum, L., Petrie, T., Soules, G., Weiss, N., 1970. A maximization technique occurring in the statistical analysis of probabilistic functions of Markov chains. Ann. Math. Stat. 41, 164-171.

Bee, M.A., Vélez, A., Forester, J.D., 2012. Sound level discrimination by gray treefrogs in the presence and absence of chorus-shaped noise. J. Acoust. Soc. Am. 131 (5), 4188-4195.

Bowling, D.L., Herbst, C.T., Fitch, W.T., 2013. Social origins of rhythm? Synchrony and temporal regularity in human vocalization. PLoS One 8 (11), e80402.

Breder, C.M., 1968. Seasonal and diurnal occurrences of fish sounds in a small Florida bay. Bull. AMNH 138 article 6.

Byers, J., Hebets, E., Podos, J., 2010. Female mate choice based upon male motor performance. Anim. Behav. 79 (4), 771-778.

Cholewiak, D., 2008. Evaluating the Role of Song in the Humpback Whale (Megaptera novaeangliae) Breeding System with Respect to Intra-Sexual Interactions.

Condit-Schultz, N., 2019. Deconstructing the nPVI: a methodological critique of the normalized pairwise variability index as applied to music. Music Percept. Interdiscip. J. 36 (3), 300-313.

Connaughton, M.A., Taylor, M.H., 1995. Seasonal and daily cycles in sound production associated with spawning in the weakfish, Cynoscion regalis. Environ. Biol. Fish 42 (3), 233-240.

Cooley, J.R., Marshall, D.C., 2001. Sexual signaling in periodical cicadas, Magicicada spp.(Hemiptera: Cicadidae). Behaviour 827-855.

de Kort, S.R., Eldermire, E.R., Valderrama, S., Botero, C.A., Vehrencamp, S.L., 2009. Trill consistency is an age-related assessment signal in banded wrens. Proc. R. Soc. B Biol. Sci. 276 (1665), 2315-2321.

dos Santos, M.E., Modesto, T., Matos, R.J., Grober, M.S., Oliveira, R.F., Canário, A., 2000. Sound production by the Lusitanian toad fish, Halobatrachus didactylus. Bioacoustics 10 (4), 309-321.

Dyson, M.L., Passmore, N.I., 1988. Two-choice phonotaxis in Hyperolius marmoratus (Anura: Hyperoliidae): the effect of temporal variation in presented stimuli. Anim. Behav. 36, 648-652.

Eckmann, J.P., Kamphorst, S.O., Ruelle, D., 1987. Recurrence plots of dynamical systems. J. Europhys. Lett. 4, 973-977.

Ferraro, S.P., 1980. Daily time of spawning of 12 fishes in the Peconic Bays, New York, USA. Fish. Bull. US 78, 455-464.

Fine, M.L., 1977. Temporal aspects of calling behavior in oyster toadfish, opsanus-tau. Fish. Bull. 75 (4), 871.

Fine, M.L., Lenhardt, M.L., 1983. Shallow-water propagation of the toadfish mating call. Comp. Biochem. Physiol. A Physiol. 76 (2), 225-231.

Fish, J.F., 1972. The effect of sound playback on the toadfish. In: Behavior of Marine Animals. Springer, Boston, MA, pp. 386-434.

Fine, M.L., Thorson, R.F., 2008. Use of passive acoustics for assessing behavioral interactions in individual toadfish. Transactions of the American Fisheries Society 137 (2), 627-637.

Fonseca, P., Alves, J., 2012. A new concept in underwater high fidelity low frequency sound generation. Rev. Sci. Instrum. 83 (5), 055007.

Forney, G., 1973. The viterbi algorithm. Proc. IEEE 6, 268-278.

Gerhardt, H., Huber, F., 2002. Acoustic Communication in Insects and Anurans: Common Problems and Diverse Solutions. The University of Chicago Press, Chicago. 
Gibson, R.N., 1982. Recent studies on the biology of intertidal fishes. Oceanogr. Mar. Biol. 20, 363-414.

Grabe, E., Low, E.L., 2002. Durational variability in speech and the rhythm class hypothesis. Pap. Lab. Phonol. 7, 515-546.

Greenfield, M., 1994. Synchronous and alternating choruses in insects and anurans: common mechanisms and diverse functions. Am. Zool. 34, 605-615.

Greenfield, M.D., Roizen, I., 1993. Katydid synchronous chorusing is an evolutionarily stable outcome of female choice. Nature 364 (6438), 618.

Hastie, T., Tibshirani, R., 1990. Generalized Additive Models. Chapman and Hall/CRC London.

Hobson, E.S., Chess, J.R., 1978. Trophic relationships among fishes and plankton in the lagoon at Enewetak Atoll, Marshall Island. Fish. Bull. 76, 133-153.

Holt, G.J., Holt, S.A., Arnold, C.R., 1985. Diel periodicity of spawning in sciaenids. Mar. Ecol. Prog. Ser. 27 (1), 7.

Jadoul, Y., Ravignani, A., Thompson, B., Filippi, P., de Boer, B., 2016. Seeking temporal predictability in speech: comparing statistical approaches on 18 world languages. Front. Hum. Neurosci. 10 (586), 1-15.

Jordão, J.M., Fonseca, P.J., Amorim, M.C.P., 2012. Chorusing behaviour in the Lusitanian toadfish: should I match my neighbours' calling rate? Ethology 118 , 885-895. https://doi.org/10.1111/j.1439-0310.2012.02078.x.

Kéver, L., Lejeune, P., Michel, L.N., Parmentier, E., 2016. Passive acoustic recording of Ophidion rochei calling activity in Calvi Bay (France). Mar. Ecol. 37 (6), 1315-1324. https://doi.org/10.1111/maec.12341.

Klump, G.M., Gerhardt, H.C., 1992. Mechanisms and function of call-timing in male-male interactions in frogs. In: Playback and Studies of Animal Communication. Springer, Boston, MA, pp. 153-174.

Leiser, J.K., 2003. When are neighbours 'dear enemies' and when are they not? The responses of territorial male variegated pupfish, Cyprinodon variegatus, to neighbours, strangers and heterospecifics. Anim. Behav. 65, 453-462.

Lobel, P.S., 1978. Diel, lunar, and seasonal periodicity in the reproductive behavior of the pomacanthid fish, Centropyge potteri, and some other reef fishes in Hawaii. Pac. Sci. 32, 193-207.

Locascio, J.V., Mann, D.A., 2011. Diel and seasonal timing of sound production by black drum (Pogonias cromis). Fish. Bull. 109 (3), 327-338.

Luczkovich, J.J., Pullinger, R.C., Johnson, S.E., Sprague, M.W., 2008. Identifying sciaenid critical spawning habitats by the use of passive acoustics. Trans. Am. Fish. Soc. 137 (2), 576-605.

Mann, D.A., 2006. Propagation of fish sounds. Commun. Fish. 1, 107-120.

Mann, D.A., Locascio, J.V., Coleman, F.C., Koenig, C.C., 2009. Goliath grouper Epinephelus itajara sound production and movement patterns on aggregation sites. Endanger. Species Res. 7 (3), 229-236.

Mann, D., Locascio, J., Schärer, M., Nemeth, M., Appeldoorn, R., 2010. Sound production by red hind Epinephelus guttatus in spatially segregated spawning aggregations. Aquat. Biol. 10 (2), 149-154.

Maruska, K.P., Mensinger, A.F., 2009. Acoustic characteristics and variations in grunt vocalizations in the oyster toadfish Opsanus tau. Environ. Biol. Fish 84 (3), 325-337.

Medina, E., Solorio, T., 2006. Wavesurfer: A Tool for Sound Analysis. UTEP, El Paso, TX.

Mensinger, A.F., 2014. Disruptive communication: stealth signaling in the toadfish. J. Exp. Biol. 217 (3), 344-350.

Mercado III, E., Handel, S., 2012. Understanding the structure of humpback whale songs (L). J. Acoust. Soc. Am. 132 (5), 2947-2950.

Miyagawa, M., Takemura, A., 1986. Acoustical behavior of the scorpaenoid fish Sebastiscus marmoratus. Bull. Jpn. Soc. Sci. Fish. 52, 411-415.

Monczak, A., Berry, A., Kehrer, C., Montie, E.W., 2017. Long-term acoustic monitoring of fish calling provides baseline estimates of reproductive timelines in the May River estuary, southeastern USA. Mar. Ecol. Prog. Ser. 581, 1-19.

Montie, E.W., Hoover, M., Kehrer, C., Yost, J., Brenkert, K., O’Donnell, T., Denson, M.R., 2017. Acoustic monitoring indicates a correlation between calling and spawning in captive spotted seatrout (Cynoscion nebulosus). PeerJ. 5, e2944.

Muller, K., 1998. The role of conspecifics in habitat settlement in a territorial grasshopper. Anim. Behav. 56, 479-485.

Norton, P., Scharff, C., 2016. "Bird song Metronomics": isochronous organization of zebra finch song rhythm. Front. Neurosci. 10, 309.

Parmentier, E., Di Iorio, L., Picciulin, M., Malavasi, S., Lagardère, J.-P., Bertucci, F., 2017. Consistency of spatiotemporal sound features supports the use of passive acoustics for long-term monitoring. Anim. Conserv. 21 (3), 211-220. https://doi. org/10.1111/acv.12362.

Parsons, M.J., Salgado-Kent, C.P., Marley, S.A., Gavrilov, A.N., McCauley, R.D., 2016. Characterizing diversity and variation in fish choruses in Darwin Harbour. ICES J. Mar. Sci. 73 (8), 2058-2074.

Pereira, B.P., Vieira, M., Pousão-Ferreira, P., Candeias-Mendes, A., Barata, M., Fonseca, P.J., Amorim, M.C.P., 2020. Sound production in the Meagre, Argyrosomus regius (Asso, 1801): intraspecific variability associated with size, sex and context. PeerJ 8, e8559.

Phillips, R.R., Swears, S.B., 1981. Diel activity cycles of two Chesapeake Bay fishes, the striped blenny (Chasmodes bosquianus) and the oyster toadfish (Opsanus tau). Estuaries 4 (4), 357-362.

Picciulin, M., Kéver, L., Parmentier, E., Bolgan, M., 2018. Listening to the Unseen: Passive Acoustic Monitoring Reveals the Presence of a Cryptic Fish Species. Marine and Freshwater Ecosystems, Aquatic Conservation. https://doi.org/10.1002/ aqc. 2973.
R Core Team, 2018. R: A Language and Environment for Statistical Computing. R Foundation for Statistical Computing, Vienna, Austria. URL. https://www.R-project. org/.

Ravignani, A., 2017. Visualizing and interpreting rhythmic patterns using phase space plots. Music Percept. Interdiscip. J. 34 (5), 557-568.

Ravignani, A., 2019. Timing of antisynchronous calling: a case study in a harbor seal pup (Phoca vitulina). J. Comp. Psychol. 133 (2), 272.

Ravignani, A., Norton, P., 2017. Measuring rhythmic complexity: a primer to quantify and compare temporal structure in speech, movement, and animal vocalizations. J. Lang. Evol. 2 (1), 4-19.

Ravignani, A., Bowling, D.L., Fitch, W., 2014. Chorusing, synchrony, and the evolutionary functions of rhythm. Front. Psychol. 5, 1118.

Ravignani, A., Kello, C.T., de Reus, K., Kotz, S.A., Dalla Bella, S., Méndez-Aróstegui, M., Rapado-Tamarit, B., Rubio-Garcia, A., de Boer, B., 2019. Ontogeny of vocal rhythms in harbor seal pups: an exploratory study. Curr. Zool. 65 (1), 107.

Remage-Healey, L., Bass, A.H., 2005. Rapid elevations in both steroid hormones and vocal signaling during playback challenge: a field experiment in Gulf toadfish. Horm. Behav. 47 (3), 297-305.

Ricci, S.W., Bohnenstiehl, D.R., Eggleston, D.B., Kellogg, M.L., Lyon, R.P., 2017. Oyster toadfish (Opsanus tau) boatwhistle call detection and patterns within a large-scale oyster restoration site. PLoS One 12 (8).

Rice, A.N., Bass, A.H., 2009. Novel vocal repertoire and paired swimbladders of the three-spined toadfish, Batrachomoeus trispinosus: insights into the diversity of the Batrachoididae. J. Exp. Biol. 212 (9), 1377-1391.

Ruppé, L., Clément, G., Herrel, A., Ballesta, L., Décamps, T., Kéver, L., Parmentier, E., 2015. Environmental constraints drive the partitioning of the soundscape in fishes. Proc. Natl. Acad. Sci. 112 (19), 6092-6097.

Ryan, M.J., Tuttle, M.D., Taft, L.K., 1981. The costs and benefits of frog chorusing behavior. Behav. Ecol. Sociobiol. 8, 273-278. https://doi.org/10.1007/ BF00299526.

Salas, A.K., Wilson, P.S., Ryan, M.J., 2018. Acoustic communication in the Bocon toadfish (Amphichthys cryptocentrus). Environ. Biol. Fish 101 (7), 1175-1193.

Sanchez-Gendriz, I., Padovese, L.R., 2017. Temporal and spectral patterns of fish choruses in two protected areas in southern Atlantic. Ecol. Inform. 38, 31-38.

Schneider, J.N., Mercado III, E., 2019. Characterizing the rhythm and tempo of sound production by singing whales. Bioacoustics 28 (3), 239-256.

Staaterman, E., Brandl, S.J., Hauer, M., Casey, J.M., Gallagher, A.J., Rice, A.N., 2018. Individual voices in a cluttered soundscape: acoustic ecology of the Bocon toadfish, Amphichthys cryptocentrus. Environ. Biol. Fish 101 (6), 979-995.

Tauber, E., 2001. Bidirectional communication system in katydids: the effect on chorus structure. Behav. Ecol. 12, 308-312.

Tellechea, J.S., Bouvier, D., Norbis, W., 2011. Spawning sounds in whitemouth croaker (Sciaenidae): seasonal and daily cycles. Bioacoustics 20 (2), 159-168.

Thorson, R.F., Fine, M.L., 2002. Acoustic competition in the gulf toadfish Opsanus beta: acoustic tagging. J. Acoust. Soc. Am. 111 (5), 2302-2307.

Todt, D., Naguib, M., 2000. Vocal interactions in birds: the use of song as a model in communication. In: Advances in the Study of Behavior. Elsevier, pp. 247-296.

Van Wert, J.C., Mensinger, A.F., 2019. Seasonal and daily patterns of the mating calls of the oyster toadfish, Opsanus tau. Biol. Bull. 236 (2), 97-107.

Vasconcelos, R.O., Simões, J.M., Almada, V.C., et al., 2010. Vocal behavior during territorial intrusions in the Lusitanian toadfish: boatwhistles also function as territorial "keep-out" signals. Ethology 116, 155-165. https://doi.org/10.1111/ j.1439-0310.2009.01722.x.

Vasconcelos, R.O., Carrico, R., Ramos, A., et al., 2011. Vocal behavior predicts reproductive success in a teleost fish. Behav. Ecol. 23, 375-383. https://doi.org/ 10.1093/beheco/arr199.

Vasconcelos, R.O., Carriço, R., Ramos, A., Modesto, T., Fonseca, P.J., Amorim, M.C.P., 2012. Vocal behavior predicts reproductive success in a teleost fish. Behav. Ecol. 23, 375-383.

Vieira, M., Fonseca, P.J., Amorim, M.C.P., Teixeira, C.J.C., 2015. Call recognition and individual identification of fish vocalizations based on automatic speech recognition: an example with the Lusitanian toadfish. J. Acoust. Soc. Am. 138, 3941-3950.

Vieira, M., Pereira, B.P., Pousão-Ferreira, P., Fonseca, P.J., Amorim, M., 2019. Seasonal variation of captive meagre acoustic signalling: a manual and automatic recognition approach. Fishes 4 (2), 28.

Vieira, M., Amorim, M., Sundelöf, A., Prista, N., Fonseca, P.J., 2020. Underwater noise recognition of marine vessels passages: two case studies using hidden Markov models. ICES J. Mar. Sci. 77 (6), 2157-2170.

Wells, K., 1977. The social behaviour of anuran amphibians. Anim. Behav. 25, 666-693.

Wiley, R., 1983. The evolution of communication: information and manipulation. In: Animal Behaviour, Vol. 2: Communication. Blackwell Publishers, Oxford, pp. 156-189.

Wilson, M., Cook, P.F., 2016. Rhythmic entrainment: why humans want to, fireflies can't help it, pet birds try, and sea lions have to be bribed. Psychon. Bull. Rev. 23 (6), 1647-1659.

Winn, H.E., 1967. Vocal facilitation and the biological significance of toadfish sounds. Mar. Bio-Acoust. 2, 283-304.

Wood, S., 2006. Low-rank scale-invariant tensor product smooths for generalized additive mixed models. Biometrics 62, 1025-1036.

Wood, S., 2017. Generalized Additive Models: An Introduction with R, 2nd ed. Chapman and Hall/CRC, London.

Young, S., Evermann, G., Gales, M., 2006. The HTK Book Version 3.4. Cambridge University Press. 